\title{
Experimental Characterization of the Flow Field around Oblong Bridge Piers
}

\author{
Ana Margarida Bento ${ }^{1,2,3, *,+(\mathbb{D}}$, Teresa Viseu ${ }^{1}\left(\mathbb{D}\right.$, João Pedro Pêgo $^{2,3}$ and Lúcia Couto $^{1} \mathbb{C}$ \\ 1 Water Resources and Hydraulic Structures Division, Hydraulics and Environment Department, \\ National Laboratory of Civil Engineering, 1700-066 Lisboa, Portugal; tviseu@lnec.pt (T.V.); \\ luciacoutoribeiro@gmail.com (L.C.) \\ 2 Hydraulics, Water Resources and Environmental Division, Civil Engineering Department, \\ Faculty of Engineering of the University of Porto, 4400-465 Porto, Portugal; jppego@fe.up.pt \\ 3 Interdisciplinary Centre of Marine and Environmental Research of the University of Porto, \\ 4450-208 Matosinhos, Portugal \\ * Correspondence: ana.bento@fe.up.pt \\ + Current address: University of Minho, ISISE, School of Engineering, Civil Engineering Department, \\ 4800-058 Guimarães, Portugal.
}

Citation: Bento, A.M.; Viseu, T.; Pêgo, J.P.; Couto, L. Experimental Characterization of the Flow Field around Oblong Bridge Piers. Fluids 2021, 6, 370. https://doi.org/ $10.3390 /$ fluids 6110370

Academic Editor: Jaan H. Pu

Received: 7 September 2021

Accepted: 12 October 2021

Published: 20 October 2021

Publisher's Note: MDPI stays neutral with regard to jurisdictional claims in published maps and institutional affiliations.

Copyright: (c) 2021 by the authors. Licensee MDPI, Basel, Switzerland. This article is an open access article distributed under the terms and conditions of the Creative Commons Attribution (CC BY) license (https:// creativecommons.org/licenses/by/ $4.0 /)$.

\begin{abstract}
The prediction of scour evolution at bridge foundations is of utmost importance for engineering design and infrastructures' safety. The complexity of the scouring inherent flow field is the result of separation and generation of multiple vortices and further magnified due to the dynamic interaction between the flow and the movable bed throughout the development of a scour hole. In experimental environments, the current approaches for scour characterization rely mainly on measurements of the evolution of movable beds rather than on flow field characterization. This paper investigates the turbulent flow field around oblong bridge pier models in a well-controlled laboratory environment, for understanding the mechanisms of flow responsible for current-induced scour. This study was based on an experimental campaign planned for velocity measurements of the flow around oblong bridge pier models, of different widths, carried out in a large-scale tilting flume. Measurements of stream-wise, cross-wise and vertical velocity distributions, as well as of the Reynolds shear stresses, were performed at both the flat and eroded bed stages of scouring development with a high-resolution acoustic velocimeter. The time-averaged values of velocity and shear stress are larger in the presence of a developed scour hole than in the corresponding flat bed configuration.
\end{abstract}

Keywords: bridge pier; flat and eroded bed; flow field; velocity profile measurements

\section{Introduction}

The presence of obstacles such as bridge foundations in rivers is often associated with local morphological changes as a result of altering the sediment-flow equilibrium at the vicinity of those hydraulic infrastructures [1,2]. The modification of local geomorphological bed characteristics, known as local scour, should be accounted for when analysing the safety of bridges due to the severe threat that the uncovering of the foundation can pose to its integrity. Local scour around piers is one of the major threats to bridge structures founded in riverbeds and is the result of the complex flow patterns around those foundations [3-5]. It is therefore important to be acquainted with the flow structure and the related scour mechanisms around bridge piers.

The formation of highly turbulent vortex systems leads to increased local velocities and bottom shear stress, which results in the formation of scour holes. The sediment entrainment and transport are then controlled by the turbulent flow field therein developed [6,7]. Once formed, the scour hole interferes significantly with the turbulent flow field and the hydrodynamic characteristics [8,9]. For instance, the bed shear stress and 
turbulence quantities are strengthened, which induces further sediment transport and scour development in the pier vicinity.

Besides the formulation of scour depth predictors, the understanding of complex turbulence patterns in the vicinity of bridge piers is also crucial in planning and designing phases of foundations' orientation, shape and geometry [6]. Several measuring techniques have been used before to characterize the flow field around piers. They began with the advent of propeller gauges, electromagnetic gauges, hot-film anemometers [10] and five-hole pitot spheres [11], and then developed to more sophisticated measuring equipment, such as Acoustic Doppler Velocimeter (ADV) [8,9,12,13], Laser Doppler Velocimetry (LDV) [14] and Particle Image Velocimetry (PIV) [15-17].

Ataie-Ashtiani and Aslani-Kordkandi [18] investigated the ADV measurements of turbulent flow field around single, side-by-side and tandem pile groups with and without a scour hole. Their results corroborated that the in-depth understanding of the flow and turbulence influenced by the scour hole is essential to improving the prediction of scour depth, see [19-21] and references therein.

The main flow processes that take place around a circular pier exposed to a steady current on a plane bed have been the subject of several flow field studies, both experimental and numerically, see [6], and references therein. They comprise the horseshoe vortices formed immediately upstream of the pier, the lee-wake vortices (usually in the form of vortex shedding), contracted streamlines at the side edges of the pier, and the downflow process due to the deceleration of the flow at the pier front. Dargahi [7] reported the result of several studies that focused on the visualization of the vertical structures around a bridge pier placed in an incoming fully turbulent flow at different stages of the scouring process. Graf and Yulistiyanto [22] measured the mean velocity components and turbulent Reynolds stresses using an ADV profiler in several planes around a circular pier for equilibrium scour conditions. By contrast, Roulund et al. [23] performed experimental and numerically visualizations of the flow in the scour hole during the evolution of the scour process and measured flow field and bed shear stresses for circular bridge piers on a flat bed. Dey and Raikar [8] have studied experimentally the structure of the turbulent horseshoe vortex flow within the developing scour holes at cylindrical piers by measuring instantaneous $3 \mathrm{D}$ velocities using an ADV. Notwithstanding, the flow in the rear part of the pier was not studied; they concluded that the flow and turbulence intensities in the horseshoe vortex remain rather similar during the development of the scour hole. While these flow structures are well-established for circular pier shape, few works have been devoted to the flow field study around bridge foundations of other shapes and geometries.

Recent studies have been focused on the characteristics of turbulence causing scour around circular, tandem, staggered arrangements and oblong piers [24,25], which did not account for the presence of scour holes. In Vijayasree et al. [24], the turbulent kinetic energy, turbulence intensities and Reynolds shear stresses were weaker for oblong piers, suggesting that this shape is a better alternative for the construction of bridge piers. The experimental work conducted by Pasupuleti et al. [25] was performed under clear water as the majority of previous research, which does not totally reproduce the field conditions. Therefore, the relatively limited number of flow field studies induced by the presence of an oblong bridge pier, most common shape of Portuguese bridge foundations of the 19th and 20th centuries, when compared with circular piers, motivated this investigation.

Therefore, the current study aims to identify and analyse the physics of the flow disturbed by the presence of a developed scour hole around oblong bridge piers. For that purpose, flow and turbulence characteristics are analysed, on the basis of an experimental campaign, concerning the change in pier effective width, approach hydraulic conditions and bed morphology stages, at the initial flat and the final eroded bed stages. Six fixed bed experiments, involving models of oblong bridge piers, were carried out in a recirculating tilting flume located in the experimental facilities of the National Laboratory of Civil Engineering (LNEC), in Lisbon, Portugal. Based on velocity measurements, the flow fields at the flume mid-plane surface were analysed, in terms of the time-averaged velocities and 
Reynolds shear stresses. Furthermore, space-averaged quantities were also obtained to clarify the influence of scour development on the flow and turbulence characteristics.

Following this introduction, the flow field experiments are characterized in Section 2. The description of the experimental facility and bridge pier models, the devices, measured variables and instrumentation, experimental procedure and conditions are given in Section 2. A particular description of the approach used for the characterization of the turbulent flow field is included in Section 3. The results and their discussion are presented in Section 4. Finally, the main conclusions of this study are provided in Section 5.

\section{Flow Field Experiments}

\subsection{Experimental Facility and Bridge Pier Models}

The experiments were undertaken in the tilting flume of LNEC (Figure 1). The tilting flume, herein termed CIV, is $40.7 \mathrm{~m}$ long, $2.0 \mathrm{~m}$ wide and $1.0 \mathrm{~m}$ deep, with glass wall sides and a concrete base.

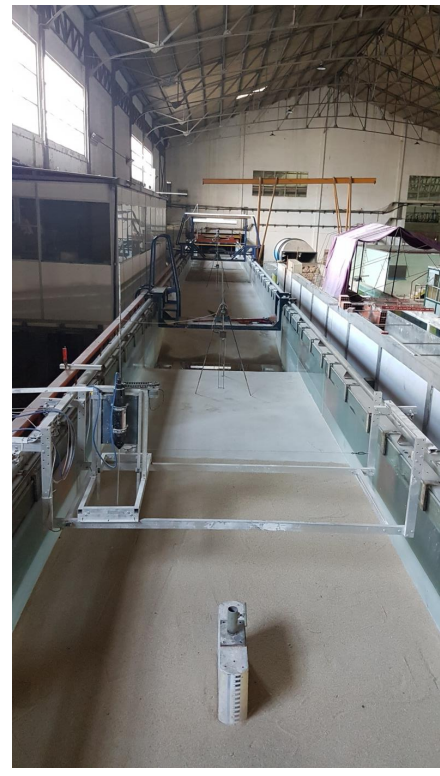

(a) Upstream working section

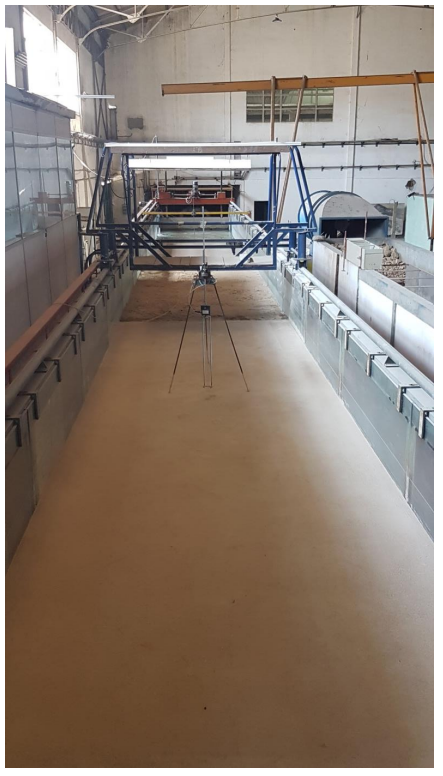

(b) View from inside.

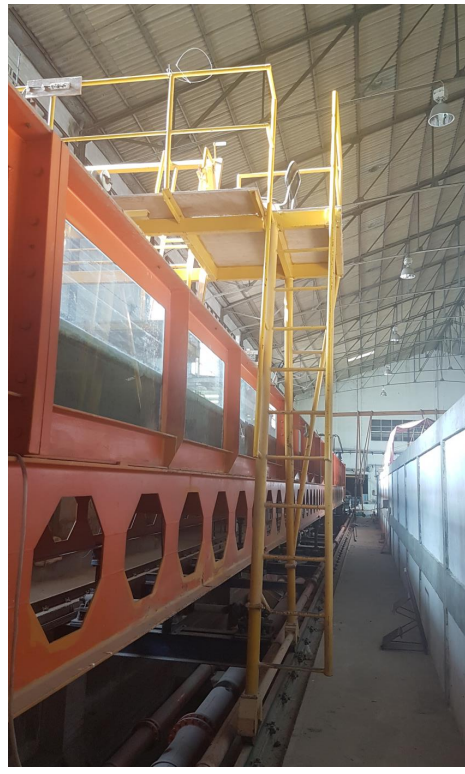

(c) View from outside

Figure 1. Experimental facility and bridge pier models.

Figure 2 presents the schematic setup of the flume. Two working sections were created within the base of the tilting flume, each being approximately $5.0 \mathrm{~m}$ long and $0.4 \mathrm{~m}$ deep. These sections were filled with uniform quartz sand characterized by a median diameter, $D_{50}$, of $0.86 \mathrm{~mm}$, a density, $\rho_{s}$, of $2650 \mathrm{kgm}^{-3}$ and a standard deviation of sediment particle sizes, $\sigma_{D}$, of 1.28. The working sections, herein also referred to as "sand recess boxes", are preceded by $2.0 \mathrm{~m}$ long accelerating ramps and $7.0 \mathrm{~m}$ long fixed bed reaches, and are followed by $3.0 \mathrm{~m}$ long fixed bed reaches. The accelerating ramps ("Acc. ramp" in Figure 2), placed at flume inlet and at the stilling recess boxes, conduce to uniform flow distributions in the two working sections. The stilling recess area between the two working sections was conceived to restore the flow regime for the downstream working section, and to store the sand bed material transported by the flowing water from the upstream working section during local scouring experiments. In the upstream boundary of the working sections, fine gravel mattresses, properly levelled by the respective concrete base, allow for smooth and progressive transitions, as well as ensure a turbulent flow development. 


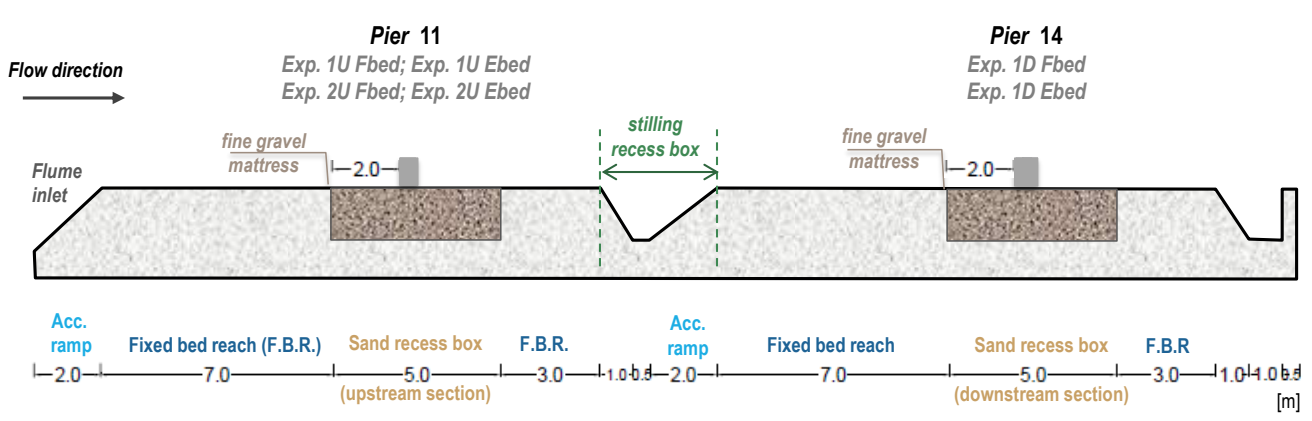

Figure 2. Schematic layout of the experimental setup (enlarged vertical scale).

Two oblong bridge pier models, Pier 11 and Pier 14, were placed in the upstream and downstream working sections, respectively. The piers differ in width $(W)$, length $(L)$, and semi-cylindrical surface ratio $(R)$, schematically identified in Figure 3 . The dimensions of Pier 11 are $W=0.11 \mathrm{~m}, L=0.433 \mathrm{~m}$ and $R=0.065 \mathrm{~m}$. Pier 14 is slightly larger, with $W=0.14 \mathrm{~m}, L=0.463 \mathrm{~m}$, and $R=0.08 \mathrm{~m}$. The bridge pier models were placed vertically on the flume mid-plane at $\approx 2 \mathrm{~m}$ from the working sections' upstream borders (Figure 2). The contraction and wall effects were negligible to the scouring process, since the associated flume "width-to-pier width" ratios ( $W / B, B$ being the flume width) were $5.5 \%$ and $7.0 \%$ (for Pier 11 and Pier 14, respectively), both lower than the limit value of $10 \%$ indicated by Chiew and Melville [26].

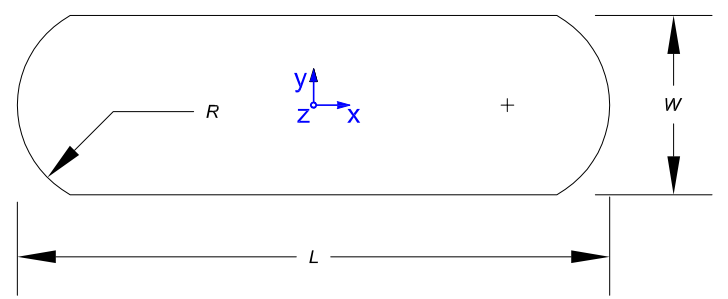

Figure 3. Geometry of the oblong bridge pier models.

The present study comprises the hydrodynamic characterization of six experiments divided into fixed flat bed and eroded bed stages of three local scouring experiments, namely Exp. $1 U, \operatorname{Exp} .1 D$ and Exp. $2 U$. The letters $U$ and $D$ denote the pier model, being $U$ for Pier 11 and $D$ for Pier 14 . These local scouring experiments are characterized in detail in Bento [27,28]. For simplicity, a suffix was added to the local scouring experiments' name. The suffix Fbed stands for the fixed flat bed, whilst Ebed denotes the fixed eroded bed experiments. Therefore, the six flow field experiments were labelled as follows: Exp. $1 U$ Fbed and Exp.1U Ebed for Exp.1U; Exp.1D Fbed and Exp.1D Ebed for Exp.1D; and Exp. $2 U$ Fbed and Exp. $2 U$ Ebed for Exp. $2 U$.

\subsection{Devices, Measured Variables and Instrumentation}

Several flow variables were measured during the experiments, namely: (i) the flow discharge at the flume entrance; (ii) the flow depth within CIV and at the immediacy of the working sections; and (iii) the instantaneous three velocity components of the flow at the piers' vicinity. The following paragraphs describe the measuring process of each variable.

A variable frequency drive was used to control the rotational speed of the pump motor in order to obtain the desired flow discharge. The approach flow discharge was then monitored by an electromagnetic flowmeter with a rate accuracy of $\pm 0.25 \%$. At the flume entrance, stilling grids and a flow straightener were provided for damping the flow containing large scale eddies, leading to vortex free uniform flow in CIV. An adjustable sluice gate at the downstream end of the flume enables obtaining the desirable flow depth within the flume. 
The approach flow depth was monitored using the acquired signals from acoustic probes, suitably positioned within the flume so as not to interfere with the development of the experiments. The signal of the three acoustic probes was acquired at a sampling frequency of $10 \mathrm{~Hz}$, whereas the signal of the electromagnetic flowmeter was acquired at $25 \mathrm{~Hz}$. Movable carriages were present on the rails of the flume to allow the access for controlling and measuring purposes of both the approach flow depth and the acquisition of the flow velocity components by the connection of the downlooking vectrino to its respective acquisition firmware (Vectrino Plus).

The instantaneous three-dimensional velocity measurements were acquired by using a high-resolution acoustic velocimeter, namely a downlooking vectrino (hereinafter designated as vectrino), from Nortek $₫$, in two different moments: (i) at the beginning of the scouring process (flat bed stage), and (ii) at the final stage of the scouring experiments (eroded bed stage). The velocity flow field was measured throughout the working section around the pier models at relative elevations for the comparison of turbulence and flow characteristics due to the scouring process (before scour vs. after scour). An independent moving carriage system was developed to clamp the vectrino in order to move it along the different velocity measurement grid points to ease the measurement task, up to an accuracy of $\pm 1 \mathrm{~mm}$ in the three directions $(x, y$ and $z)$. This issue will be considered in more detail in Section 3. The origin was considered at the pier centre, where $x, y$ and $z$ denote the longitudinal, transversal and vertical axes, respectively (see Figure 3).

\subsection{Experimental Procedure}

To facilitate the performance of the experiments on fixed beds, the surface layers of the bed material (Step 1-Figure 4a) were frozen by spraying uniformly a synthetic glue over the bed morphology stages (flat and eroded). This practice is frequently used in flow field studies under the assumption that the results are simpler and more explanatory than those from complex scenarios with a variety of acting processes, such as sediment burial and reappearance processes [29], and references therein.

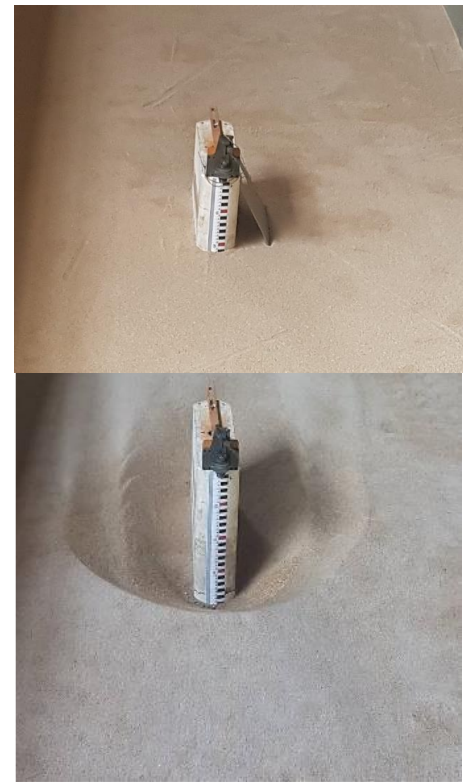

(a) Step 1

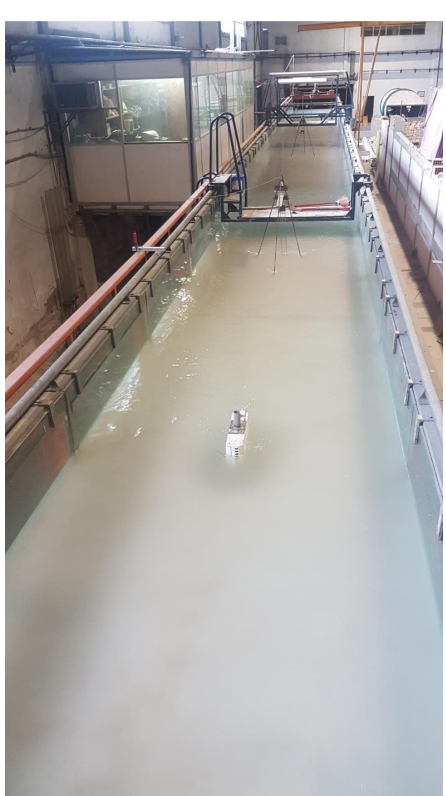

(b) Step 2

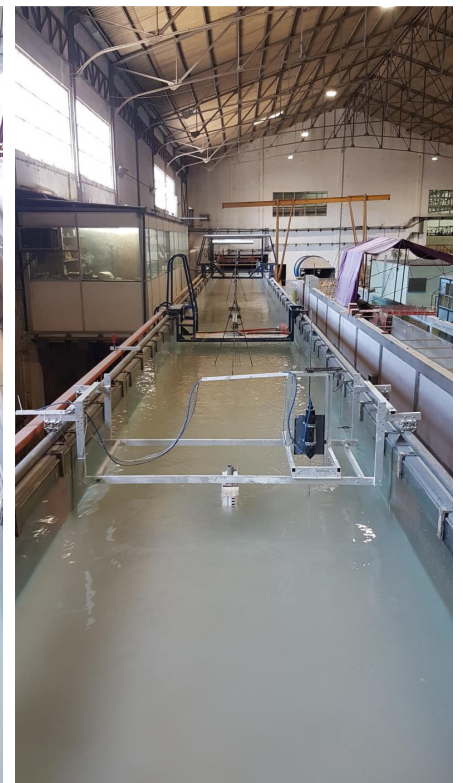

(c) Step 3

Figure 4. Setup for the flow velocity measurements.

Once the sand beds were properly stabilized, after approximately $72 \mathrm{~h}$, the same hydraulic conditions of the corresponding local scouring experiments $[27,28]$ were imposed, and the flume was filled up to the desired flow discharge and flow depth (conditions referred later). Since the vectrino uses the Doppler effect to measure current velocity by transmitting short pairs of acoustic waves, they must bounce off from particulate 
matter in the flow. As the laboratory water was quite clean, an artificial introduction of particles (commonly known as seeding particles) was deemed necessary, and thus a silica powder was added to the flow. An indicative aspect of the quality of the seeded flow is the parameter signal-to-noise ratio (SNR), provided by the Vectrino Plus interface; the higher the SNR, the better the seeding, and consequently, the more reliable the velocity measurements (Step 2-Figure 4b).

Five acoustic probe tips (one transmitter and four receivers, illustrated in Figure 4c) send and receive acoustic information in a fluid volume below the vectrino, referred to as the sampling volume. Since the instrument is inserted into the flow, the sampling volume must be sufficiently far away from the probe tip so as not to disturb the flow and the velocity measurements. Using acoustic waves, the vectrino takes real-time measurements (Step 3-Figure 4c). To evaluate quality of velocity measurements, one of the real-time outputs that vectrino provides is a correlation statistic. This is a value ranging from $0 \%$ to $100 \%$; the closer the correlation is to $100 \%$, the less noisy and more reliable a velocity measurement is. A minimum correlation of $70 \%$ is strongly recommended by several researchers [12], among others, and thus considered in the present study. In addition, a minimum signal-to-noise ratio $(S N R)$ of $15 \mathrm{~dB}$ was designated for ensuring the reliability of the instantaneous velocity data $[30,31]$.

Before conducting each experiment, several trials were undertaken to estimate the uncertainty in the measurement sampling duration. To tackle this, an assessment of the signal acquisition time's influence on the statistics of turbulent quantities was performed in Bento et al. [32]. Thus, signal acquisition times within the range of 120 to $300 \mathrm{~s}$ were considered in order to achieve time-independent velocity components, regarding the magnitude of turbulence at each measuring location. The vectrino was operated with an acoustic frequency of $10 \mathrm{MHz}$ and a sampling rate of $200 \mathrm{~Hz}$.

Besides the flow velocity characterization of the six fixed bed experiments by a comprehensive measuring system (resumed later), the flow depth was also continuously monitored for ensuring the predefined hydraulic conditions. After the completion of each fixed bed experiment, the surface layers of the sand beds were removed, the sand box re-levelled and once again fixed by the synthetic glue (to perform the corresponding flat bed experiment). A careful re-establishment of the hydraulic conditions was performed with a gradual filling of the flume.

\subsection{Hydraulic Conditions and Time Duration}

Table 1 presents the main hydraulic variables of the fixed bed experiments, namely the approach flow discharge $(Q)$, flow depth $(h)$, flow velocity $(V)$, Froude number $(F r=V / \sqrt{g h})$, flow Reynolds number $(R e=V h / v$, being $v$ the kinematic viscosity of the fluid), and the parameter concerning the relation with the pier model: the pier Reynolds number $\left(R e_{D}=V W / v\right)$. In Table 1 , these parameters are given with a $95 \%$ of confidence interval; the estimated error corresponded to the sample error, expressed as $1.96 \sigma / \sqrt{n_{S}}$ (being $\sigma$ the standard deviation and $n_{s}$ the sample size).

The flow depth within CIV was considered as the arithmetic average of the acoustic probes data for Exp. 1U Fbed, Exp. 1U Ebed, Exp. 1D Fbed, Exp. 1D Ebed, Exp. 2U Fbed and Exp. $2 U$ Ebed experiments. These analyses constitute a relevant and efficient source of information to account for the uncertainty in the hydraulic conditions of each experiment. The characterization of the experimental error and propagation of uncertainty demonstrated that the variability of the hydraulic variables, particularly flow discharge, flow depth, and flow velocity, had no impact on the final results (Table 1).

The oblong bridge pier models behaved as narrow or transitional [1], depending on the resultant flow shallowness ratios $(h / W)$. A flow shallowness of 1.13 was obtained for Exp. 1D Fbed and Exp. 1D Ebed (transitional piers), while values varying between 1.40 and 1.48 were attained for the remaining experiments (narrow pier category).

The flume width-to-flow depth ratios $(B / h)$ ensured negligible effects of the secondary currents due to flume side walls on the flow. Values of 12.4, 12.3, 12.6, 12.7, 10.2 and 13.5 
were obtained, respectively, for Exp.1U Fbed, Exp.1U Ebed, Exp.1D Fbed, Exp.1D Ebed, Exp. 2U Fbed and Exp. 2U Ebed (Table 1). In accordance with Yang et al. [33], that effect is solely noticeable for ratios of less than 6 . The flow was, thus, free from the secondary currents at the flume mid-plane [34], where the pier models were installed. Fully developed incoming flows were obtained for all experiments, as indicated by the magnitudes of the flow and pier Reynolds number $\left(R e\right.$ and $\left.R e_{D}\right)$ in Table 1 . The values of Froude number $(F r)$ lower than unity confirms the subcritical flow for experiments.

Table 1. Hydraulic variables of the fixed bed experiments.

\begin{tabular}{|c|c|c|c|c|c|c|c|}
\hline Experiment & Pier (-) & $Q\left(\mathrm{~m}^{3} \mathrm{~s}^{-1}\right)$ & $h(\mathrm{~m})$ & $V\left(\mathrm{~ms}^{-1}\right)$ & $\operatorname{Fr}(-)$ & $\operatorname{Re}(-)$ & $\operatorname{Re}_{D}(-)$ \\
\hline Exp.1U Fbed & Pier 11 & .0927 & $0.1610 \pm 3 \times 10^{-6}$ & $0.2882 \pm 6 \times 10^{-6}$ & $0.1825 \pm 8 \times 10^{-6}$ & $46,200 \pm 0.06$ & $31,600 \pm 0.7$ \\
\hline Exp.1U Ebed & Pier 11 & 0.0925 & $0.1628 \pm 3 \times 10^{-6}$ & $0.2849 \pm 4 \times 10^{-6}$ & $0.1784 \pm 4 \times 10^{-6}$ & $46,200 \pm 0.02$ & $31,200 \pm 0.4$ \\
\hline Exp. 1D Fbed & Pier 14 & 0.0927 & $0.1588 \pm 5 \times 10^{-6}$ & $0.2921 \pm 9 \times 10^{-6}$ & $0.1875 \pm 1 \times 10^{-6}$ & $46,200 \pm 0.1$ & $32,000 \pm 1.0$ \\
\hline Exp.1D Ebed & Pier 14 & 0.0925 & $0.1579 \pm 3 \times 10^{-6}$ & $0.2937 \pm 5 \times 10^{-6}$ & $0.1896 \pm 6 \times 10^{-6}$ & $46,200 \pm 0.05$ & $32,200 \pm 0.5$ \\
\hline Exp. $2 U$ Fbed & Pier 11 & $0.1244 \pm 5 \times 10^{-7}$ & $0.1952 \pm 1 \times 10^{-5}$ & $0.3187 \pm 2 \times 10^{-5}$ & $0.1665 \pm 2 \times 10^{-5}$ & $61,900 \pm 0.2$ & $34,900 \pm 2.0$ \\
\hline Exp. $2 U$ Ebed & Pier 11 & $0.1237 \pm 4 \times 10^{-7}$ & $0.1486 \pm 5 \times 10^{-7}$ & $0.4164 \pm 2 \times 10^{-6}$ & $0.2856 \pm 2 \times 10^{-6}$ & $61,600 \pm 0.18$ & $45,600 \pm 0.2$ \\
\hline
\end{tabular}

\section{Flow Field Characterization}

In the present research, instantaneous velocity maps were acquired for the fixed bed experiments, before the beginning of the scouring process, at a flat bed, and at the final stage of experiments, at an eroded bed. Figure 5 provides a schematic diagram of the velocity point measurements. It comprises five half-planes, namely $A, J, E, G$ and $I$. Each half-plane is composed by 4 or 5 vertical profiles, as indicated in Figure 5 , where the flow velocity was measured for several points along the water depth. The position of the measuring spots varied for each application; it was dependent on flow depth and pier dimensions. In line with what was performed in the works of Kirkil et al. [35], Chang et al. [36], and Beheshti and Ataie-Ashtiani [13], among others, the measurements in each experiment were taken in the Cartesian coordinate system $(x, y, z)$ also indicated in Figure 5. Further details can be found in Bento [28].

A minimum correlation of $70 \%$ and a minimum signal-to-noise ratio (SNR) of $15 \mathrm{~dB}$ were thus considered for ensuring the reliability of the instantaneous velocity data $[30,31]$. During the velocity measurements, the downlooking vectrino sampling frequency was chosen to be $200 \mathrm{~Hz}$ with a duration within the range of 120 to $300 \mathrm{~s}$, depending on the magnitude of turbulence at each measuring location. These instantaneous threedimensional velocity measurements allowed obtaining: (i) mean velocities $(u, v$ and $w)$; (ii) turbulent fluctuation velocities $\left(u^{\prime}, v^{\prime}\right.$ and $\left.w^{\prime}\right)$; and (iii) Reynolds shear stresses (RSSes) including $\overline{u^{\prime} v^{\prime}}, \overline{u^{\prime} w^{\prime}}$ and $\overline{v^{\prime} w^{\prime}}$. The derivation of such parameters provides insights of the flow magnitude and structure for the particularities of each experiment and bed morphology stage (before vs after scour).

Prior to data analysis, all records were visually inspected to identify potential erroneous data such as spikes, trends or abrupt discontinuities in the velocity time series. The velocity data was then processed, which streamlined the analysis of the turbulent and the time-averaged 3D velocity data, as well as the statistical and the spectral analysis of the downlooking vectrino data by computing the respective skewness and kurtosis measures for each measuring point. Results including mean values, variance, skewness and kurtosis of each of the aforementioned variables, for all experiments, can be found in Database S1 in the Supplementary Materials. For the sake of simplicity, a limited number of the most relevant plots is analysed in Section 4, namely for the different vertical profiles of the half-planes $A$ and $J$. A total of 680 velocity point measurements were acquired for these two half-planes. For each vertical profile, a relative study on the characteristic flow and turbulence quantities is conducted, regarding the bridge's effective width, approach flow condition and bed configuration (flat $v$ s eroded), addressed in Section 4. 


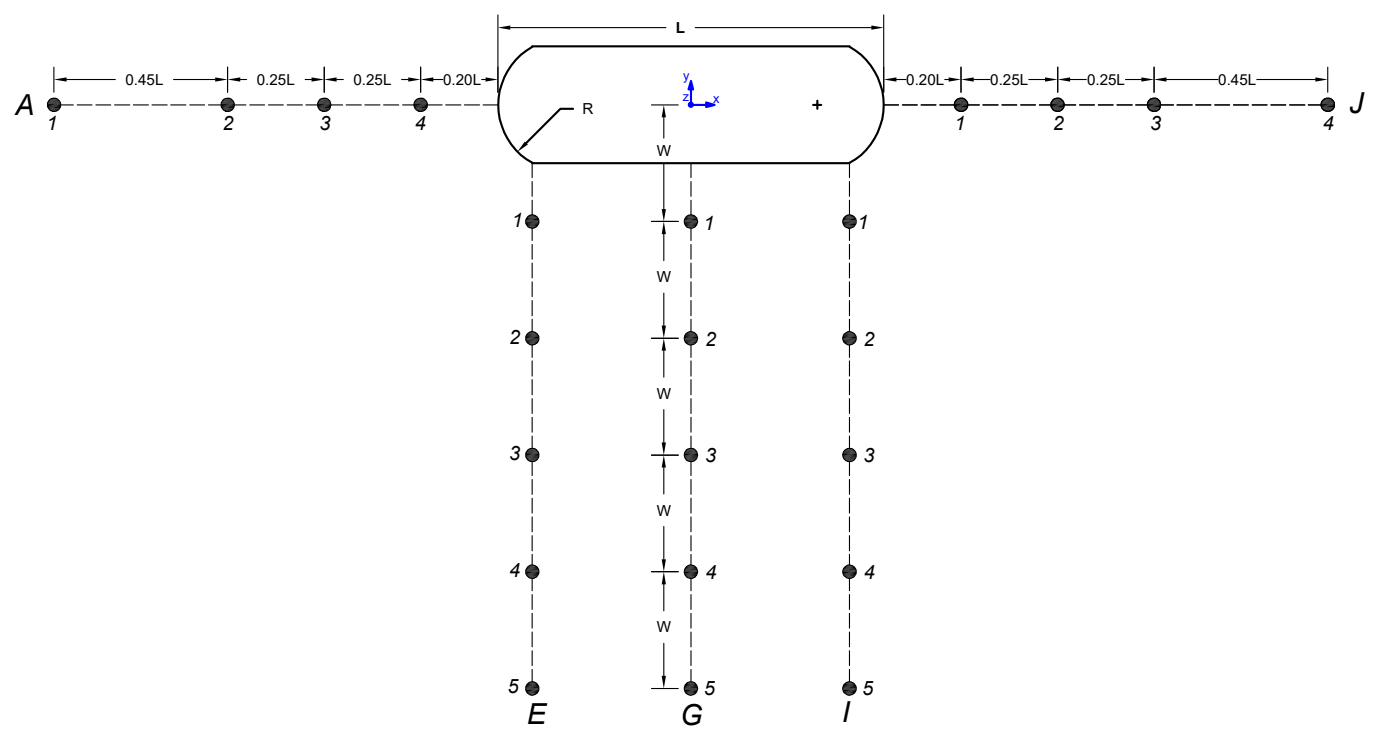

Figure 5. Schematic diagram of the velocity point measurements. Profiles on the longitudinal halfplanes $(A$ and $J)$ are numbered from left to right, while those on the transversal half-planes $(E, G$, and $I$ ) are numbered from the pier outwards.

A characterization of the approach flow was also performed. For fully turbulent flow, over hydraulically rough sand bed surface, the dimensionless stream-wise mean velocity $\left(u / u^{*}\right.$, being $u^{*}$ the shear velocity), was found to follow the log-law as expected, see [37] and references therein. The roughness coefficient value adopted, $k_{s}$, was $0.00215 \mathrm{~m}\left(k_{s}=\right.$ $2.5 D_{50}$ ). The adjustment of the log-law to Exp. $1 U$ Ebed velocity profile upstream the Pier 11 's front, for instance, allowed obtaining the shear velocity, $u^{*}$, of 0.0174 and constant $B_{s}$ $=9.74$, as shown in Figure 6 . These values, along with the bed Reynolds number, $u^{*} k_{s} / v$ $\approx 37$, are in agreement with the literature for the hydraulically transitional boundary layer [38].

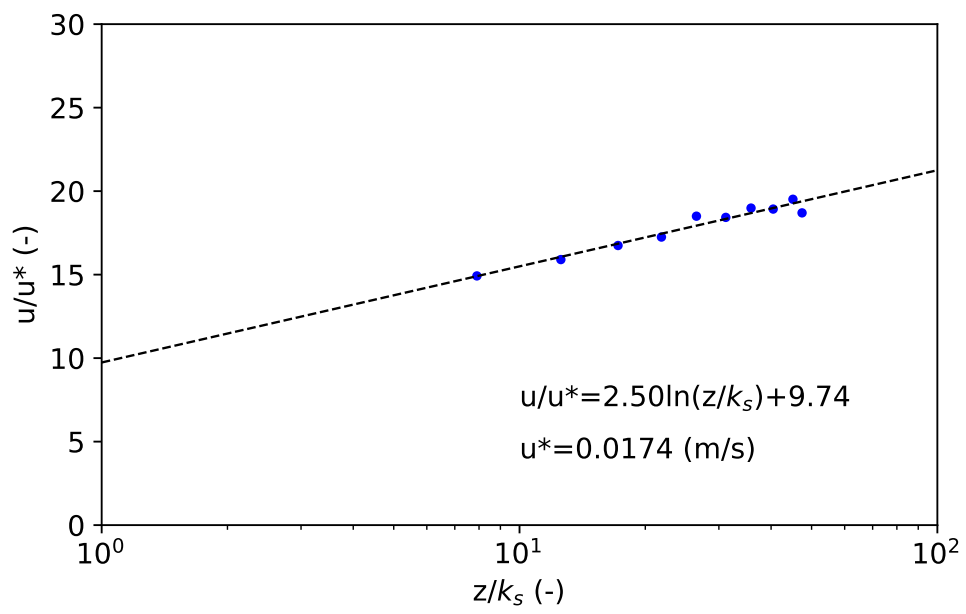

Figure 6. Longitudinal velocity profile measured in the flume mid-plane and the distance $0.50 \mathrm{~m}$ upstream the Pier 11's front. Experimental data (०) and theoretical approximation line (dashed line).

\section{Results and Discussion}

\subsection{Mean Velocities}

Figures 7-9 depict the profiles of the velocity components at the eight mid-plane vertical profiles- $A$ and $J$ half-planes (Figure 5) -for the three flat bed experiments: Exp. $1 U$ Fbed, Exp. 1D Fbed and Exp. $2 U$ Fbed. The velocity points were scaled by a reference velocity magnitude of $0.30 \mathrm{~ms}^{-1}$. 


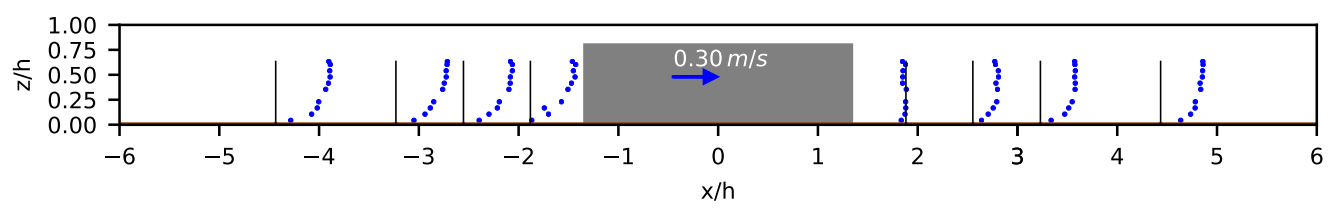

(a)

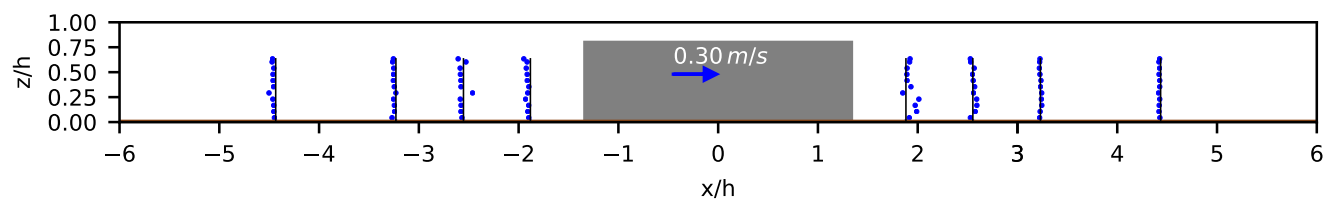

(b)

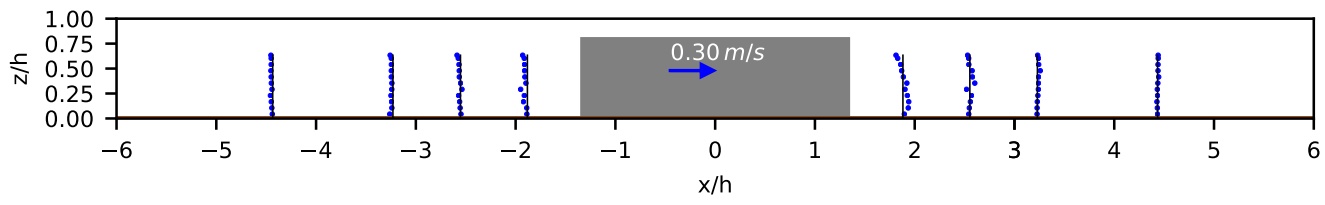

(c)

Figure 7. Vertical profiles of the velocity components along the pier's mid-plane for Exp. 1U Fbed. (a) Stream-wise component of velocity $(u)$. (b) Cross-wise component of velocity $(v)$. (c) Vertical component of velocity $(w)$.

In the upstream area, the stream-wise component of the velocity $(u)$ increases with the distance from the bed to an elevation near the flow height. Along the mid-plane surface, it decreases with proximity to the oblong bridge pier model, due to the effect of velocity reduction close to the pier's blocking effect (Figures 7a, 8a and 9a). The flat bed experiments, Exp. 1U Fbed, Exp. 1D Fbed and Exp. $2 U$ Fbed, exhibit nearly the same pattern. The $u$ vertical profile is diminished for Exp. 1D Fbed when compared with the Exp. 1U Fbed experiment. This can be attributed to large flow shallowness of Exp. 1U Fbed $(h / W=1.45)$ when compared with the correspondent value for Exp. $1 D$ Fbed $(h / W=1.14)$. The higher mean approach flow velocity of Exp. 2U Fbed (in the order of 20\%) justifies an increment of approximately $34 \%$ of the mean values of each of the four vertical profiles upstream the bridge pier model (Pier 11).

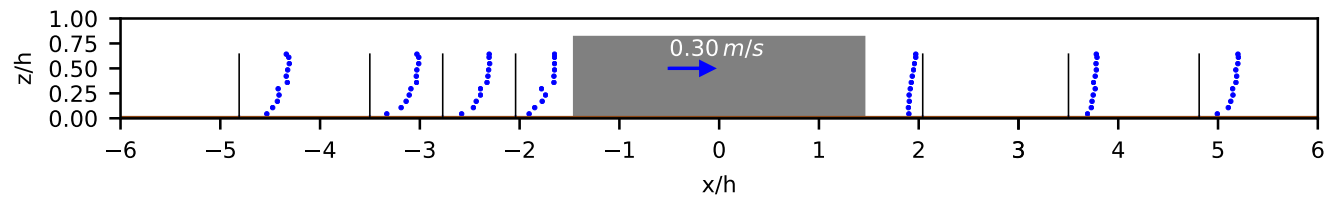

(a)

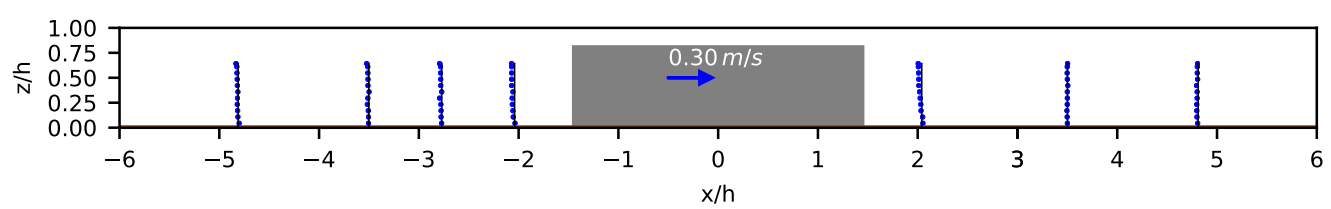

(b)

Figure 8. Vertical profiles of the velocity components along the pier's mid-plane for Exp. 1D Fbed. (a) Stream-wise component of velocity $(u)$. (b) Vertical component of velocity $(w)$. 


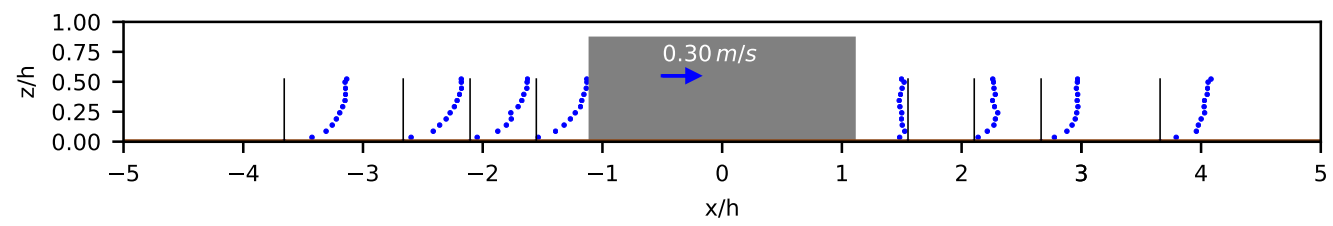

(a)

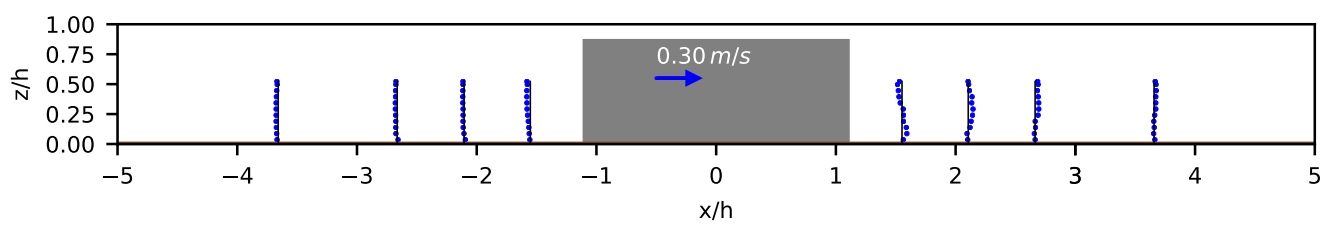

(b)

Figure 9. Vertical profiles of the velocity components along the pier's mid-plane for Exp. $2 U$ Fbed. (a) Stream-wise component of velocity $(u)$. (b) Vertical component of velocity $(w)$.

In Exp. 1U Fbed, the maximum stream-wise component of velocity, $u$, occurred for an elevation $(z)$ equal to $0.097 \mathrm{~m}$ in all the vertical profiles at the upstream side of the oblong pier (Pier 11); the magnitude reached a maximum value of $0.377 \mathrm{~ms}^{-1}$ (skewness and kurtosis coefficients of -0.70 and 1.02 , respectively) for the vertical profile " 1 " of the $A$ halfplane (situated $0.5 \mathrm{~m}$ upstream from the pier front edge, Figure 4), whereas a magnitude of $0.313 \mathrm{~ms}^{-1}$ (skewness and kurtosis coefficients of 2.55 and 39.43, respectively) was attained for the vertical profile " 4 " of the $A$ half-plane (at roughly $0.09 \mathrm{~m}$ upstream from the pier front edge. For Exp. $2 U$ Fbed, those values registered a maximum of $0.509 \mathrm{~ms}^{-1}$ and $0.422 \mathrm{~ms}^{-1}$ for the vertical profiles " 1 " and " 4 " of $A$, respectively. The corresponding computed skewness and kurtosis coefficients were -0.94 and 2.31 for vertical profile " 1 " and -1.99 and 17.42 for vertical profile " 4 ").

Statistical moments, such as skewness and kurtosis coefficients, differing from zero means that the temporal distributions of $u$ (for the previously mentioned example) were slightly skewed and sharpened, especially for the points measured at the vertical profile " 4 ". For the corresponding velocity-point measurements, the $v$ statistical moments were closer to zero (see Database S1: Flow field database). Even though observed deviations from the Gaussian distribution [39,40] are relatively small, they may reflect significant features of the large-scale turbulence dynamics. According to Nikora et al. [39] and references therein, large-scale vortices or coherent structures enhance the kurtosis coefficient, which is also corroborated by the aforementioned statistical results. Further comparisons can be undertaken for the remaining experiments.

The stream-wise component of velocity in the downstream region of the pier models presents a similar pattern between the three experiments: a general increase of $u$ as the vertical profiles move away from the oblong bridge pier. However, it should be noted that for profile " 1 " of the $J$ half-plane (see Figures $7 a, 8 a$ and $9 a$ ), in all three flat bed experiments, alternate positive and negative values were observed along the vertical profile, which can be attributed to the effect of the shedding vortexes therein developed. In line with Figure 5, the vertical profiles " 1 " of $J$ half-planes are situated at $0.087 \mathrm{~m}$ and $0.093 \mathrm{~m}$ from the downstream end of Pier 11 and Pier 14, respectively.

The time average $v$ values at the symmetry plane $(y=0)$ are nearly zero, as expected (Figure $7 \mathrm{~b}$ ) and reported in previous research, such as Beheshti and Ataie-Ashtiani [13] and Pandey et al. [41]. For that reason, the $v$ vertical distributions from the remaining flat bed experiments (Exp.1D Fbed and Exp. 2U Fbed) are not herein depicted.

The vertical profiles of the $w$-component velocity, represented in Figures $7 \mathrm{c}, 8 \mathrm{~b}$ and $9 \mathrm{~b}$, illustrate the downward movement of flow (downflow) in front of the respective oblong bridge pier models. The $w$ component is highest for Exp. $2 U$ Fbed, as compared to the other 
two experiments (Exp.1U Fbed and Exp.1D Fbed, respectively). In those, the smaller values are attributed to the areas with less scouring near the pier as the stream bed surface did not permit the flow acceleration in the downward direction of the pier model. These results are in line with previous studies such as Dey and Raikar [8].

Figures 10-12 illustrate the distribution of the velocity components at the same eight mid-plane vertical profiles, from the $A$ and $J$ half-planes (as previously performed), for the three eroded bed experiments: Exp. $1 U$ Ebed, Exp.1D Ebed and Exp. $2 U$ Ebed. Similarly, the velocity points were scaled by a reference velocity magnitude of $0.30 \mathrm{~ms}^{-1}$, except for Exp. $2 U$ Ebed, where a value of $0.40 \mathrm{~ms}^{-1}$ was considered.

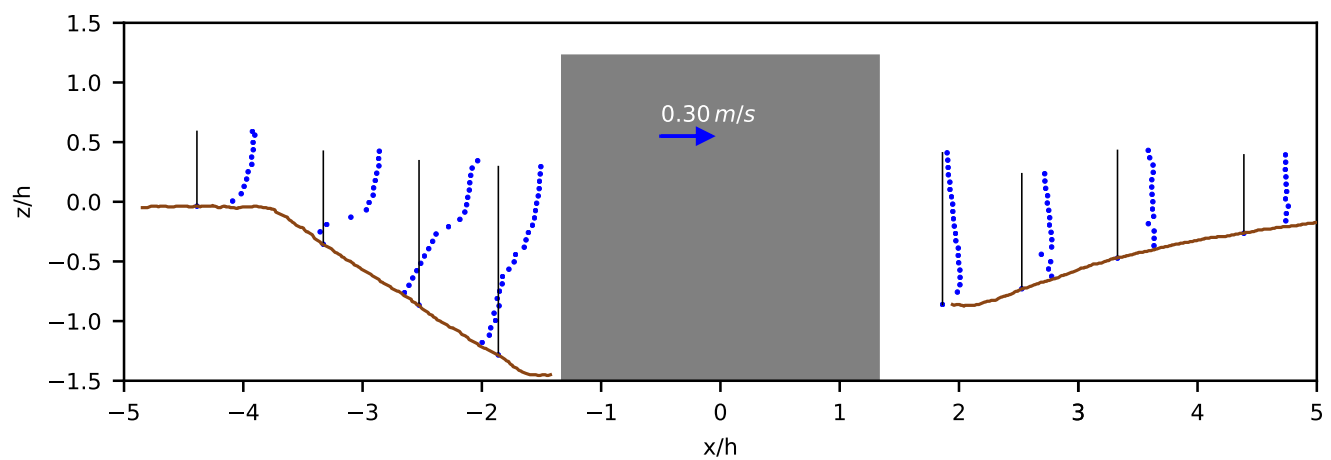

(a)

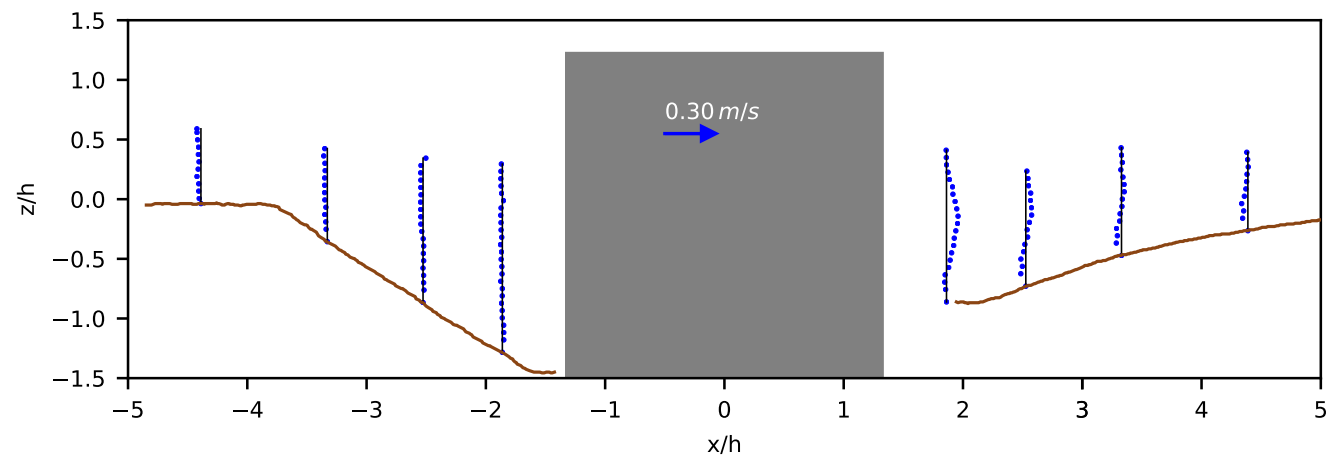

(b)

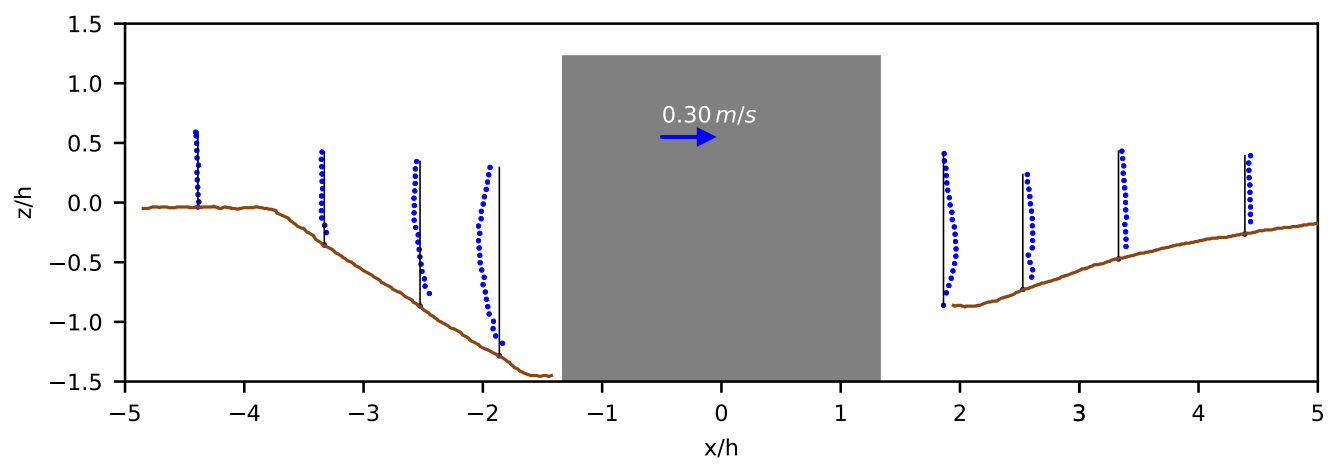

(c)

Figure 10. Vertical profiles of the velocity components along the pier's mid-plane for Exp. 1U Ebed. (a) Stream-wise component of velocity $(u)$. (b) Cross-wise component of velocity $(v)$. (c) Vertical component of velocity $(w)$. 


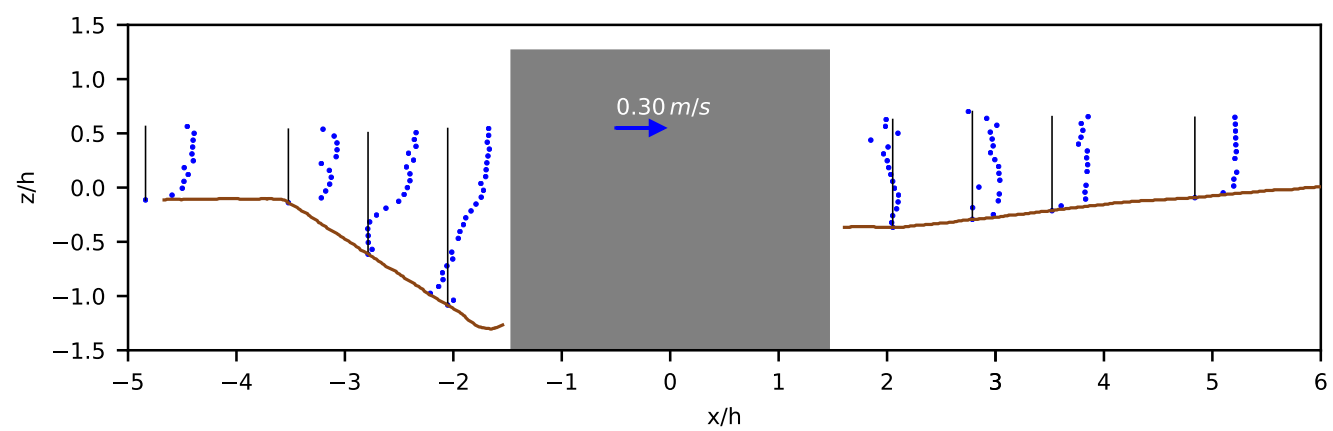

(a)

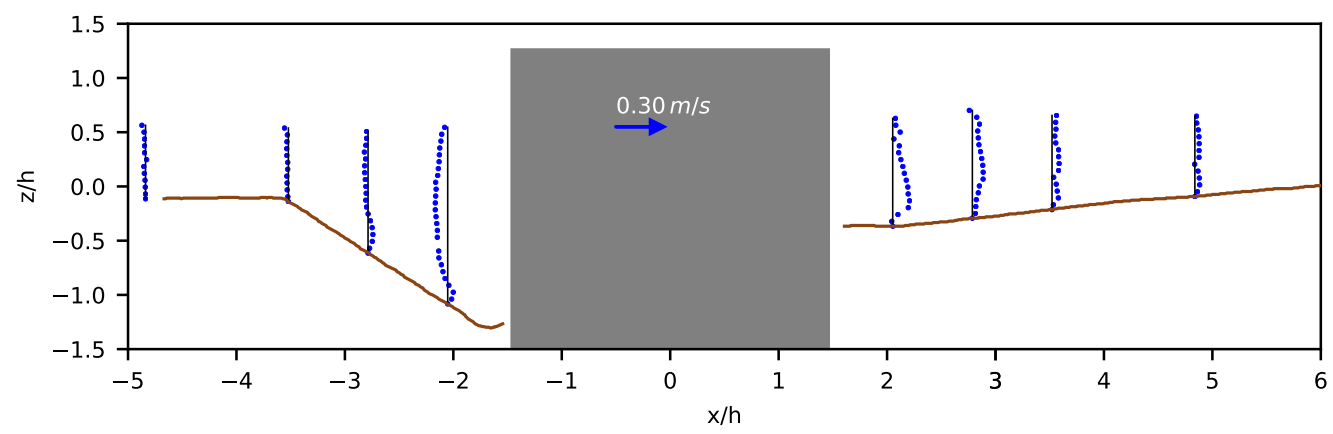

(b)

Figure 11. Vertical profiles of the velocity components along the pier's mid-plane for Exp. 1D Ebed. (a) Stream-wise component of velocity $(u)$. (b) Vertical component of velocity $(w)$.

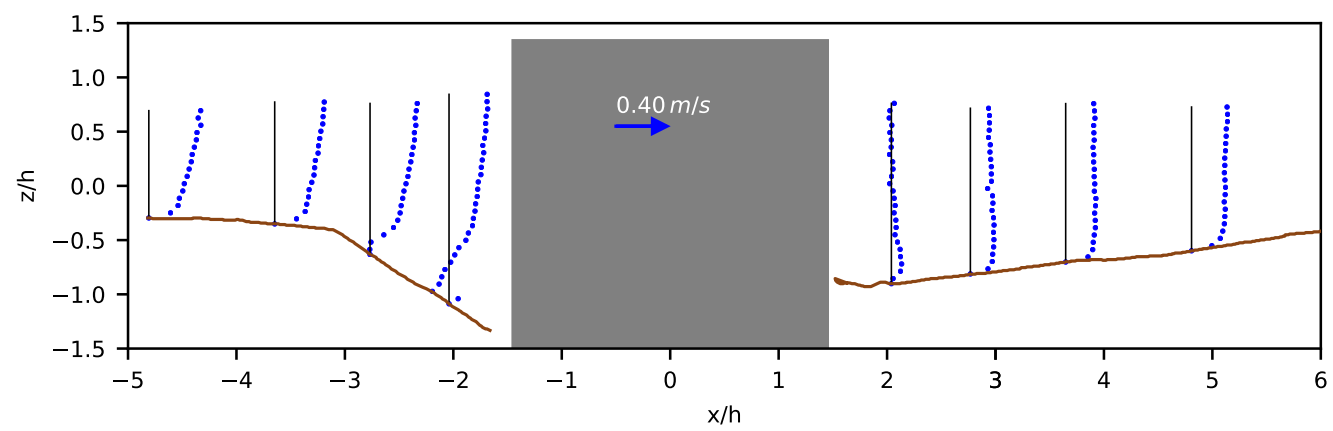

(a)

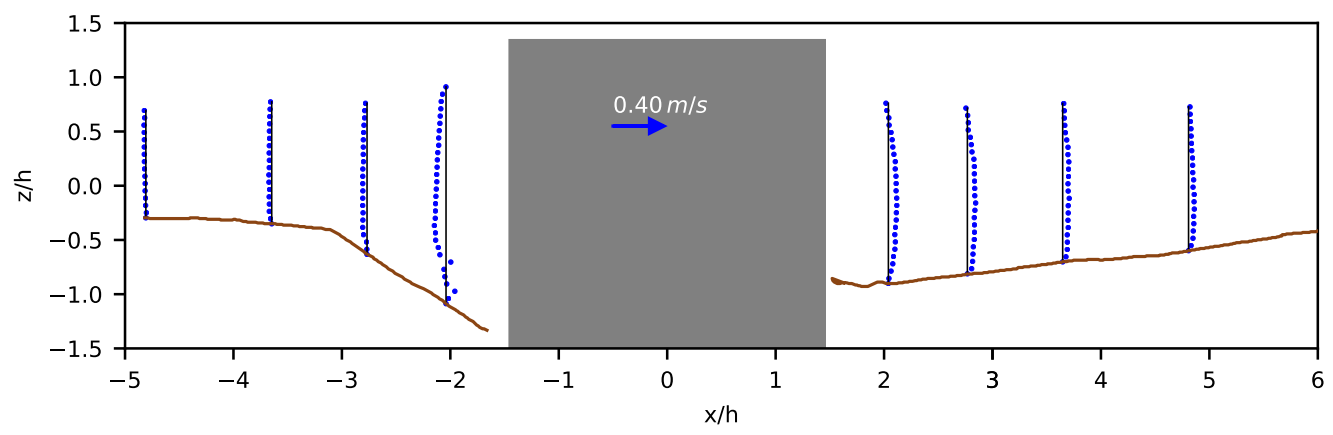

(b)

Figure 12. Vertical profiles of the velocity components along the pier's mid-plane for Exp. $2 U$ Ebed. (a) Stream-wise component of velocity $(u)$. (b) Vertical component of velocity $(w)$. 
Unlike in other flow field experimental studies, see [21] and references therein, the velocity measurements were also allowed within the scour hole of the eroded bed experiments, which explains the negative values for elevations $z$ below the initial flat bed level (see Figures 10-12). As can be observed, vertical profile " 1 " of $A$ is situated outside the upstream border of the scour hole in all experiments. The remaining vertical profiles of $A$ and $J$ half-planes are placed within the eroded scour holes.

The stream-wise velocity $(u)$ profiles are marked by negative velocity within the developed scour holes, which indicates the occurrence of flow separation and recirculation, as can be seen in Figures 10a, 11a and 12a. Besides the roughly same approach hydraulic conditions of Exp.1U Ebed and Exp.1D Ebed, the corresponding flow shallowness values fit into distinct pier categories; the pier models behave as narrow pier for Exp. $1 U$ Ebed and transitional pier category for Exp. 1D Ebed. As initially stated by Raudkivi [42] and corroborated by several other researchers ([43], and references therein), the parameter $h / W$ affects the vorticity, which is associated with the generation of scour. For decreasing flow shallowness values, the influence of the surface roller on the bed increases, damping the vortices in front of the pier and consequently explaining the slightly lower $u$ values.

A region of reversal flow was noticeable at vertical profile " 4 " of the $A$ half-plane (immediately upstream from the pier), then it moved further upstream from the pier towards the scour hole edge. The $u$ magnitudes generally increase with larger scour hole dimensions; thus, higher values were obtained for Exp. $2 U$ Ebed. This can be explained that as the scour evolves upstream, the bed slope increases due to the formation of the scour hole, and the flow velocity increases correspondingly [21]. In Figures 10a, 11a and 12a, the downstream vertical profiles of $u$ (from $J$ half-plane in Figure 5) are characterized by increasing magnitudes as they move away from the oblong bridge pier models.

As performed for Exp. 1U Fbed, the $v$ profile of Exp. 1U Ebed (shown in Figure 10b) was analysed and a similar behaviour (showing negligible changes) was observed. Hence, the remaining $v$ profiles were not represented.

The vertical profiles of the $w$-component velocity illustrate the downward movement of flow (downflow) in front of the pier (attaining its maximum value for vertical profile "4" of $A$ half-plane in all eroded bed experiments). The downward vertical velocity increased with the scour hole dimension, registering the maximum value for Exp. $2 U$ Ebed. This finding is consistent with the results from the measurement of Dey and Raikar [8] and Li et al. [21]. Downstream of the oblong bridge pier models, $w$ decreases with $x / h$ for all experiments (Exp. 1U Ebed, Exp. 1D Ebed and Exp. $2 U$ Ebed), thus reducing the lifting action. This pattern is more pronounced for the eroded bed experiments (with developed scour holes) than for the corresponding flat bed configurations.

To sum up, the mean flow velocities for the six fixed experiments indicate that with the developed scour hole, the downward flow in front of the oblong bridge pier model becomes more prominent, and the flow becomes more turbulent due to the effect of a turbulent horseshoe vortex within the scour hole, as documented by previous researchers [21,43], among others.

\subsection{Reynolds Shear Stresses}

The time-averaged Reynolds shear stresses, $\overline{u^{\prime} v^{\prime}}, \overline{u^{\prime} w}$ and $\overline{v^{\prime} w^{\prime}}$, are depicted in Figures 13-15 for experiments Exp. 1U Fbed, Exp. 1D Fbed and Exp. 2U Fbed, respectively.

The comparative study of $\overline{u^{\prime} v^{\prime}}, \overline{u^{\prime} w^{\prime}}$ and $\overline{v^{\prime} w^{\prime}}$ along the pier's mid-plane for the eroded bed experiments was also performed, as illustrated in Figures 16-18 for Exp. 1U Ebed, Exp. $1 D$ Ebed and Exp. $2 U$ Ebed, respectively. 


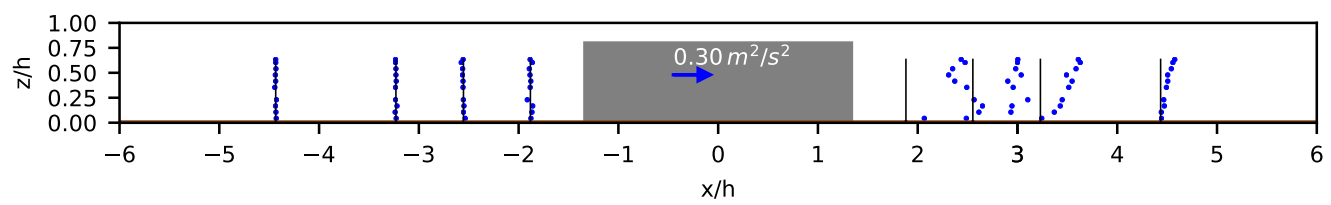

(a)

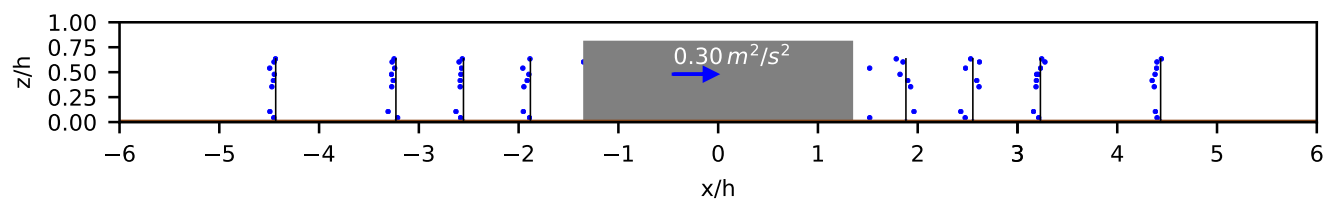

(b)

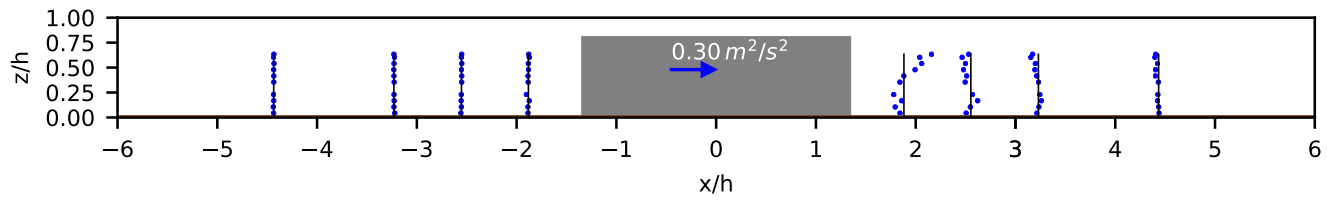

(c)

Figure 13. Vertical profiles of the Reynolds shear stresses along the pier's mid-plane for Exp. 1U Fbed. (a) Reynolds shear stresses $\left(\overline{u^{\prime} v^{\prime}}\right)$. (b) Reynolds shear stresses $\left(\overline{u^{\prime} w^{\prime}}\right)$. (c) Reynolds shear stresses $\left(\overline{v^{\prime} w^{\prime}}\right)$.

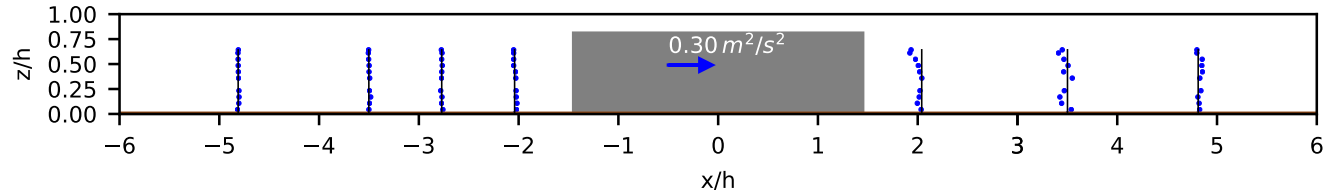

(a)

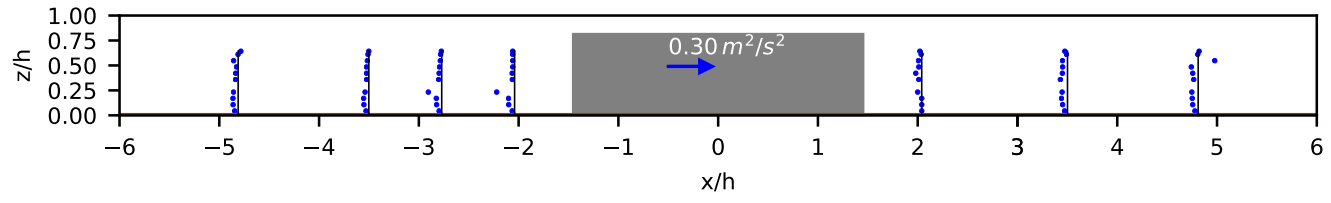

(b)

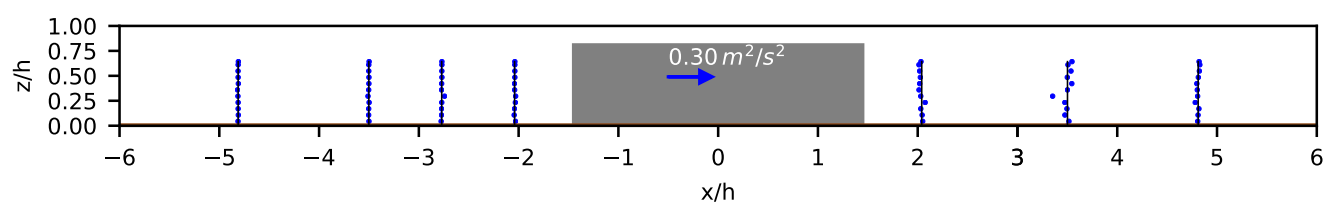

(c)

Figure 14. Vertical profiles of the Reynolds shear stresses along the pier's mid-plane for Exp. 1D Fbed. (a) Reynolds shear stresses $\left(\overline{u^{\prime} v^{\prime}}\right)$. (b) Reynolds shear stresses $\left(\overline{u^{\prime} w^{\prime}}\right)$. (c) Reynolds shear stresses $\left(\overline{v^{\prime} w^{\prime}}\right)$. 


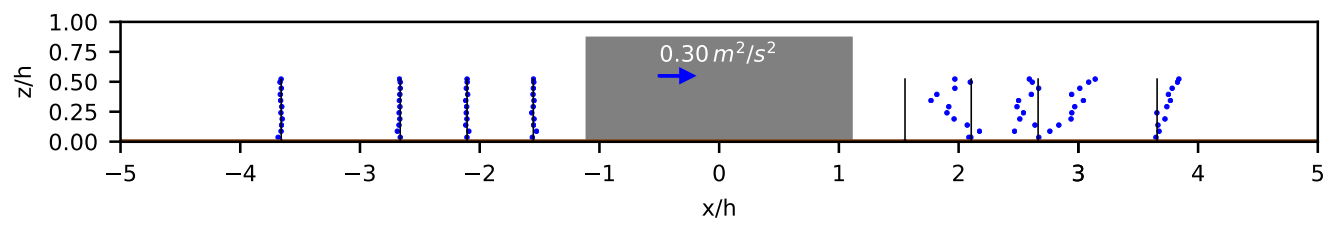

(a)

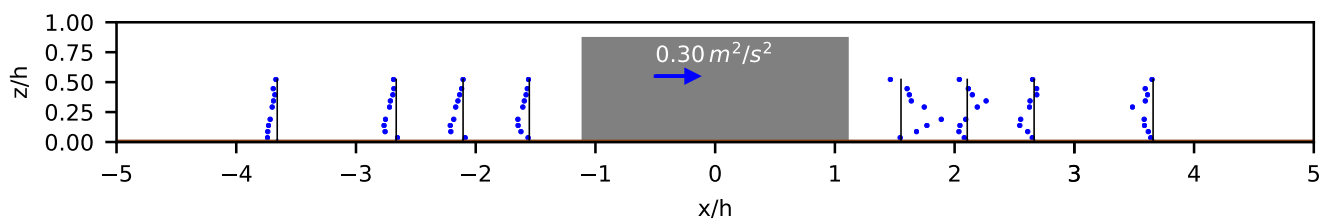

(b)

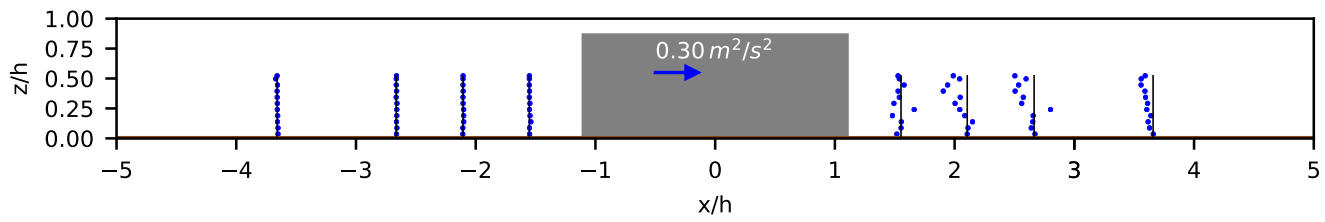

(c)

Figure 15. Vertical profiles of the Reynolds shear stresses along the pier's mid-plane for Exp. $2 U$ Fbed. (a) Reynolds shear stresses $\left(\overline{u^{\prime} v^{\prime}}\right)$. (b) Reynolds shear stresses $\left(\overline{u^{\prime} w^{\prime}}\right)$. (c) Reynolds shear stresses $\left(\overline{v^{\prime} w^{\prime}}\right)$.

Bearing in mind that the Reynolds shear stresses are linked to the capacity of the stream to transport sediments and indicate the exchange of turbulent momentum between layers of a stream $[44,45]$, it is understandable that such capacity increases with the developing scour holes, and the region with large value enlarges and moves upstream of the correspondent scour hole.

According to Figures 13-18, no significant changes were observed in the vertical profiles of Reynolds shear stresses for different bed configurations (flat $v$ s eroded). In the downstream region, the magnitudes of $\overline{u^{\prime} v^{\prime}}$ are greater than the corresponding points at the upstream side of the bridge pier model at both bed configurations (flat $v$ s eroded). This behaviour can be attributed to the turbulent mix of fluid as a result of vortical flow in the rear side of the pier. For vertical profiles of the $J$ half-plane (Figure 5), the complex flow is distinctly identified by the saw-toothed trend of the Reynolds shear stress $\overline{u^{\prime} w^{\prime}}$, magnified for the eroded fixed bed experiments. The values of $\overline{v^{\prime} w^{\prime}}$ are generally less pronounced than the other components of the Reynolds shear stress, $\overline{u^{\prime} v^{\prime}}$ and $\overline{u^{\prime} w^{\prime}}$. These results, from Figure 13-18, demonstrate that the usual assumption of isotropic turbulence is not exactly true, although it is most used as the basis of much of the theoretical analysis of turbulent flow.

Therefore, the location of the regions of the maximum Reynolds shear stresses $\left(\overline{u^{\prime} w^{\prime}}\right.$ vertical profiles) occurs at the interfaces of the negative and positive velocity components, meaning that the velocity in this region can be very unstable. This pattern was also observed in Guan et al. [46], where the turbulent flow field, in a developing clear water (with a flow intensity of 0.53 ), was quantified at a circular pier.

In spite of several studies discussing the individual trends of each component of the Reynolds shear stresses, there are few authors that argue that on the mid-plane (i.e., $y=0$ ), the Reynolds shear stresses involving the lateral fluctuations $v^{\prime}$ (i.e., $\overline{u^{\prime} v^{\prime}}$ and $\overline{v^{\prime} w^{\prime}}$ ) must be zero for symmetry reasons. In the present study, those components differed from zero mainly for the vertical profiles of the $J$ half-plane. Nevertheless, this issue has not been yet thoroughly understood in the literature. It seems that theoretically the non-zero values are 
solely related with a signal acquiring time, of the instantaneous velocity components, not long enough to obtain reliable statistics. Further and detailed investigations regarding that issue are still needed.

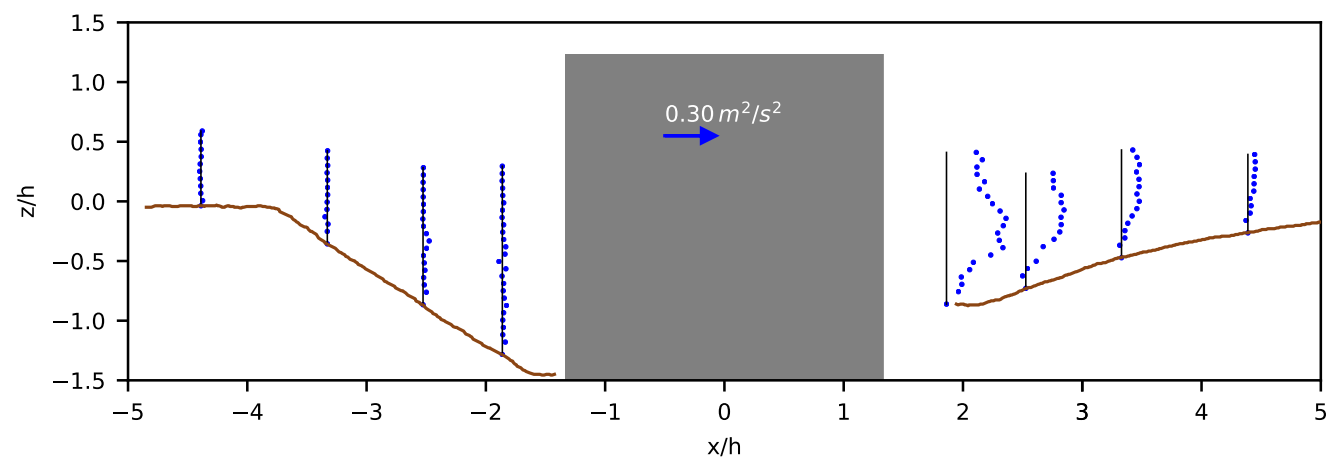

(a)

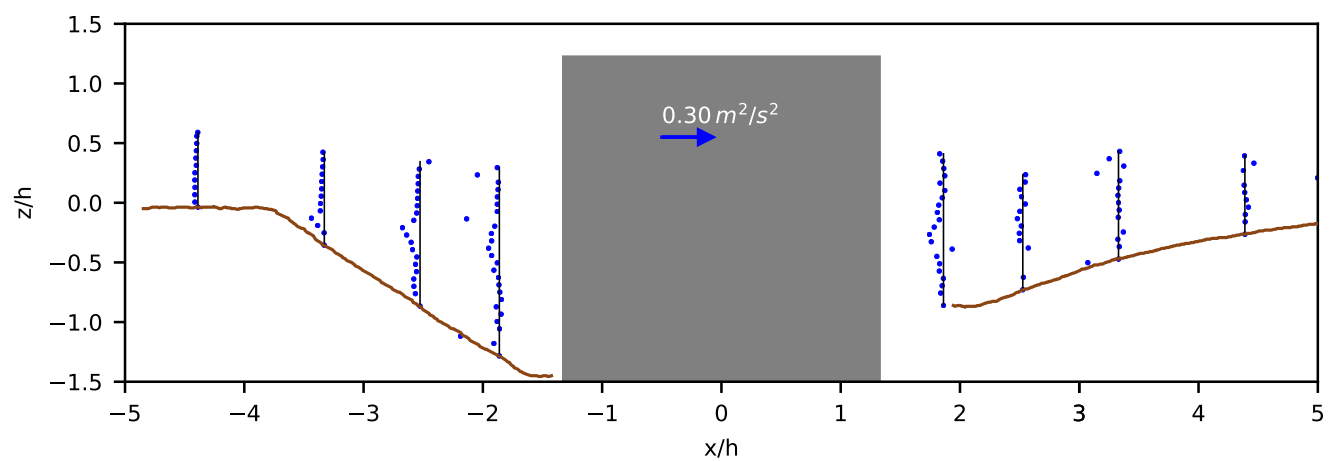

(b)

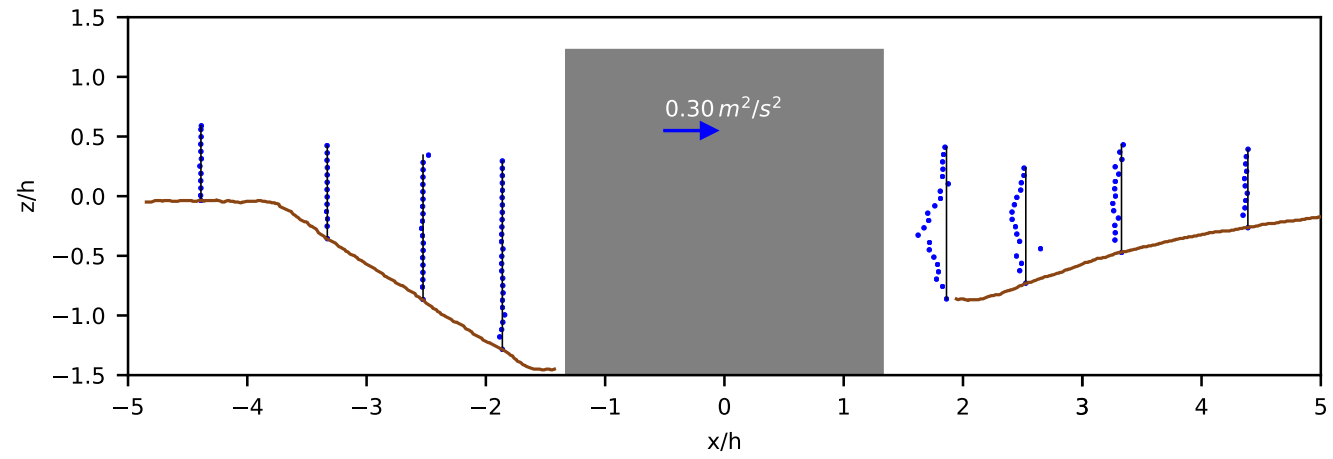

(c)

Figure 16. Vertical profiles of the Reynolds shear stresses along the pier's mid-plane for Exp. 1U Ebed. (a) Reynolds shear stresses $\left(\overline{u^{\prime} v^{\prime}}\right)$. (b) Reynolds shear stresses $\left(\overline{u^{\prime} w^{\prime}}\right)$. (c) Reynolds shear stresses $\left(\overline{v^{\prime} w^{\prime}}\right)$. 


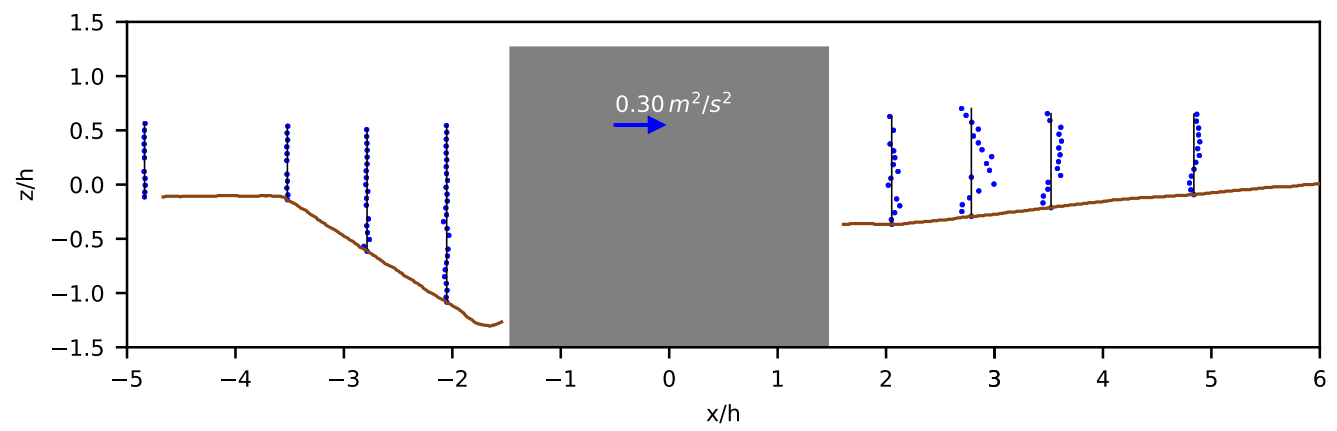

(a)

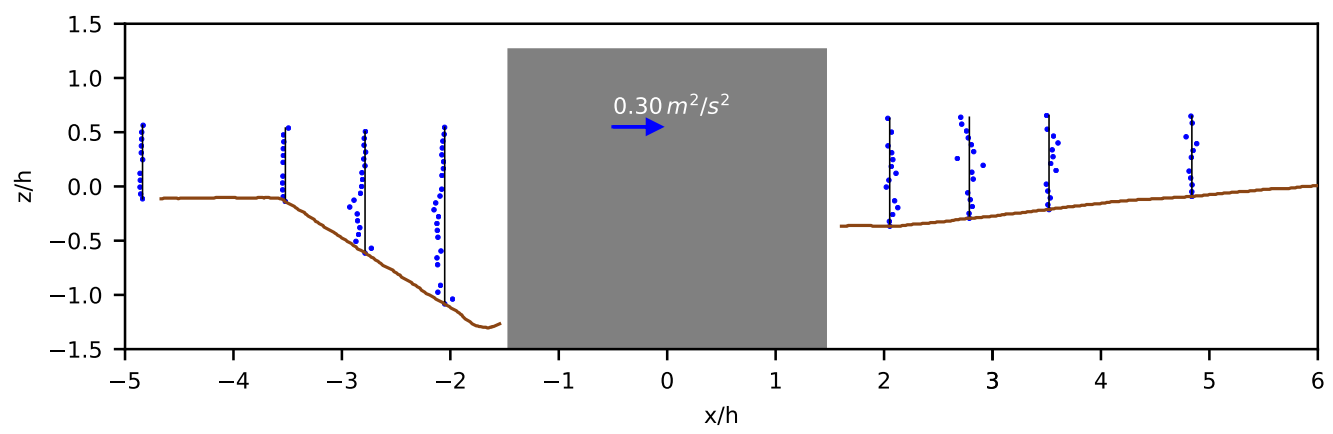

(b)

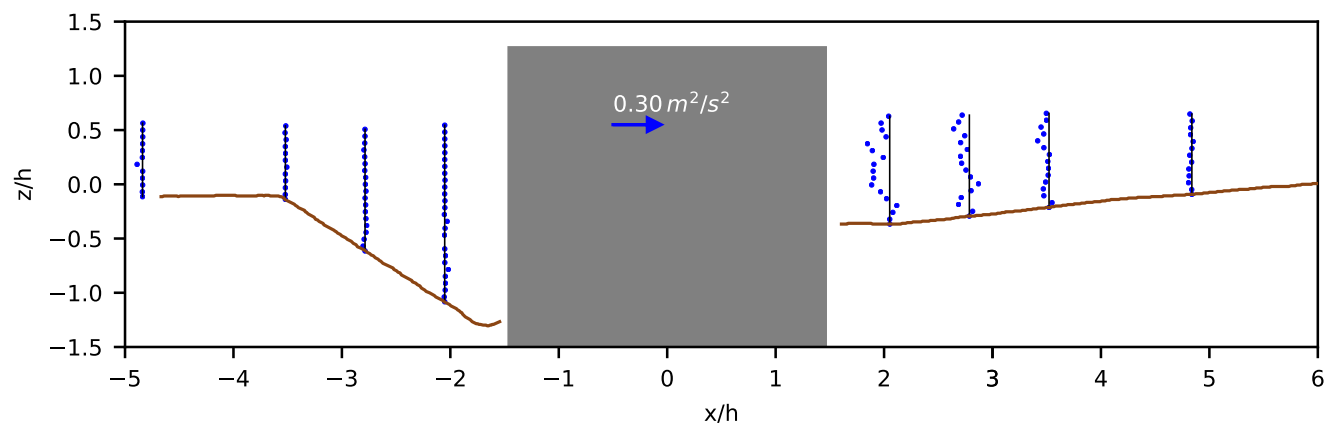

(c)

Figure 17. Vertical profiles of the Reynolds shear stresses along the pier's mid-plane for Exp. $1 D$ Ebed. (a) Reynolds shear stresses $\left(\overline{u^{\prime} v^{\prime}}\right)$. (b) Reynolds shear stresses $\left(\overline{u^{\prime} w^{\prime}}\right)$. (c) Reynolds shear stresses $\left(\overline{\bar{v}^{\prime} w^{\prime}}\right)$. 


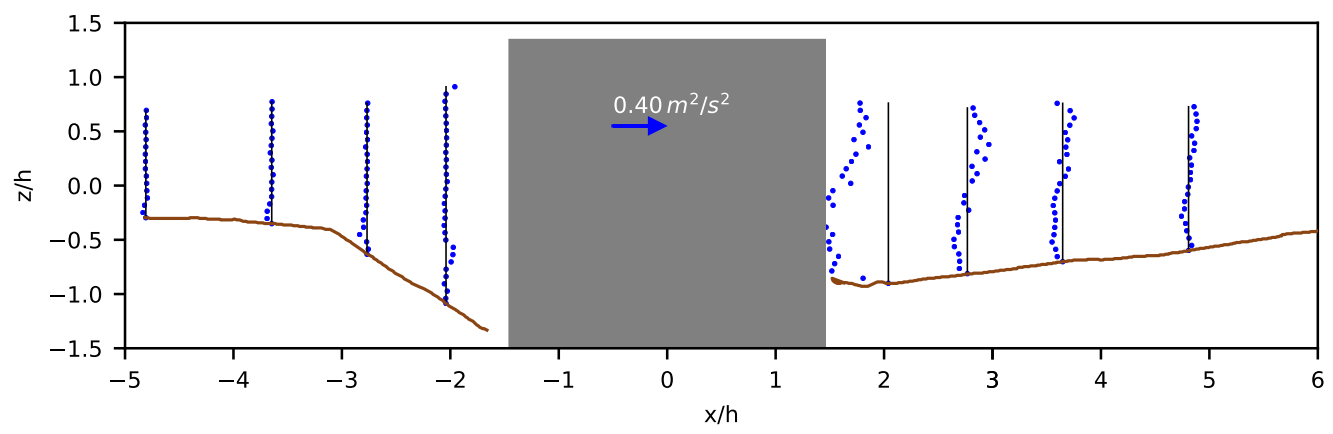

(a)

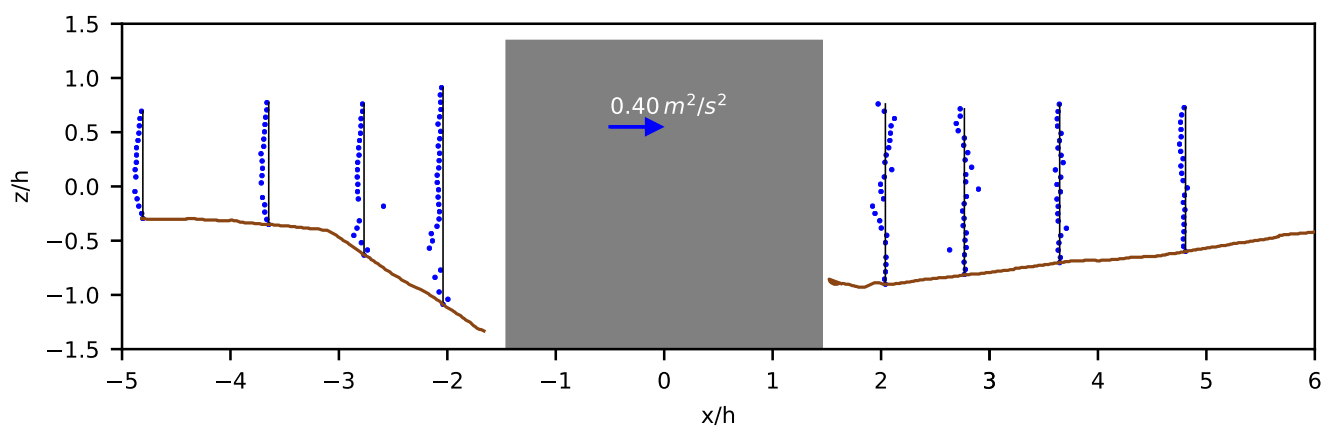

(b)

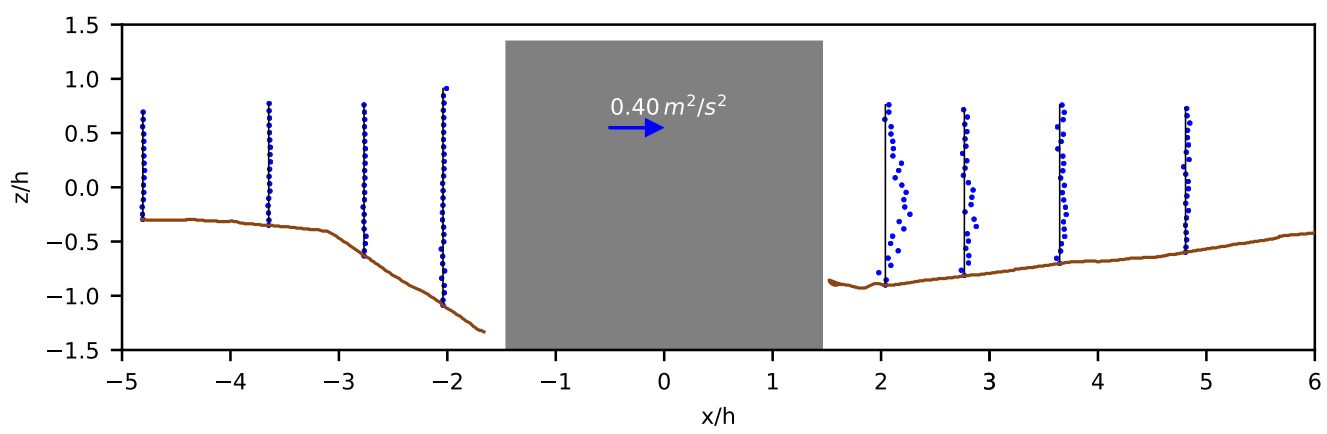

(c)

Figure 18. Vertical profiles of the Reynolds shear stresses along the pier's mid-plane for Exp. $2 U$ Ebed. (a) Reynolds shear stresses $\left(\overline{u^{\prime} v^{\prime}}\right)$. (b) Reynolds shear stresses $\left(\overline{u^{\prime} w^{\prime}}\right)$. (c) Reynolds shear stresses $\left(\overline{v^{\prime} w^{\prime}}\right)$.

\section{Conclusions}

This paper investigates the turbulent flow field around oblong bridge pier models in a well-controlled laboratory environment, for understanding the mechanisms of flow responsible for current-induced scour. Two different bed morphology configurations, namely (i) at the beginning of the scouring process (flat bed) and (ii) at the final stage of the scouring experiments (eroded bed) of the three local scouring experiments were herein considered. A total of six fixed bed experiments at the vicinity of the oblong bridge pier models of distinctive effective width and corresponding flow shallowness were carried out.

Measurements of the instantaneous stream-wise, cross-wise and vertical components of the flow velocity were performed by using a high-resolution acoustic velocimeter (downlooking vectrino) at eight mid-plane vertical profiles. The results showed that the presence of the developed scour hole, by creating extra flow resistance and augmenting the velocity difference within the four vertical profiles at the upstream side of the pier, changes the velocity distribution pattern and the Reynolds shear stresses. At the rear part of the pier, 
significant differences in flow field patterns, due to the presence of the developed scour holes, were also observed. Their magnitudes were in accordance with the approach flow conditions, such as the corresponding depth and velocity.

An important contribution was made to the understanding of the physics of the flow and turbulence characteristics with respect to the change in pier effective width, approach hydraulic conditions and bed morphology stages. The derivation of mean velocities and Reynolds shear stresses, around the oblong bridge pier models, contributes to a comprehensive description of the flow magnitude and structure for the particularities of each experiment and bed morphology stage (flat $v s$ eroded). The collected data may also constitute a basis for the calibration and validation of numerical models, frequently used to characterize the scouring phenomenon, such as Computational Fluid Dynamics (CFD) tools.

In future work, a spectra analysis of the velocity measurements, and corresponding Reynolds shear stresses, at several points, both at the upstream and downstream sides of the oblong bridge pier models, can be performed. Such analysis aids the evaluation of the shedding frequency of the large scale coherent structures and further understands the turbulent dynamics, and the inertial sub-ranges of turbulence due to the scouring phenomena.

Supplementary Materials: The following are available online at www.mdpi.com/xxx/s1, Database S1: Flow field database.

Author Contributions: Conceptualization, A.M.B., T.V., J.P.P. and L.C.; methodology and design, A.M.B., T.V., J.P.P. and L.C.; formal analysis, A.M.B.; investigation, A.M.B.; writing—original draft preparation, A.M.B.; writing-review and editing, T.V., J.P.P. and L.C. All authors have read and agreed to the published version of the manuscript.

Funding: This research was funded by the Portuguese Foundation for Science and Technology (FCT) grants number PD/BD/127798/2016, UIDB/04423/2020 and UIDP/04423/2020.

Institutional Review Board Statement: Not applicable.

Informed Consent Statement: Not applicable.

Data Availability Statement: The data presented in this study are available on reasonable request from the authors.

Acknowledgments: The first author thanks the financial support of the Portuguese Foundation for Science and Technology (FCT), through the Ph.D. scholarship PD/BD/127798/2016. This research was co-supported by strategical funding from FCT UIDB/04423/2020 and UIDP/04423/2020. We would also like to thank the team of the Laboratory of Construction and Modelling of the National Laboratory of Civil Engineering (LNEC) for the technical assistance in the experimental work.

Conflicts of Interest: The authors declare no conflict of interest.

\section{Abbreviations}

The following abbreviations are used in this manuscript:

$\begin{array}{ll}B & \text { Flume width } \\ B_{S} & \text { Constant of log-law profile } \\ D & \text { Pier Model (Pier 14) } \\ D_{50} & \text { Median grain size diameter } \\ F r & \text { Froude number } \\ g & \text { Gravity acceleration } \\ h & \text { Flow depth } \\ K_{S} & \text { Roughness coefficient } \\ L & \text { Oblong bridge pier length } \\ n_{S} & \text { Sample size } \\ Q & \text { Flow discharge } \\ R & \text { Pier semi-cylindrical surface ratio } \\ R e & \text { Flow Reynolds number }\end{array}$




$\begin{array}{ll}R e_{D} & \text { Pier Reynolds number } \\ U & \text { Pier Model (Pier 11) } \\ u & \text { Stream-wise velocity component } \\ u^{\prime} & \text { Stream-wise velocity fluctuation } \\ u^{*} & \text { Shear velocity } \\ V & \text { Approach flow velocity } \\ v & \text { Cross-wise velocity component } \\ v^{\prime} & \text { Cross-wise velocity fluctuation } \\ W & \text { Oblong bridge pier width } \\ w & \text { Vertical velocity component } \\ w^{\prime} & \text { Vertical velocity fluctuation } \\ x & \text { Longitudinal axis } \\ y & \text { Transversal axis } \\ z & \text { Vertical axis } \\ v & \text { Fluid kinematic viscosity } \\ \rho_{s} & \text { Sediment density } \\ \sigma & \text { Standard deviation } \\ \sigma_{D} & \text { Standard deviation of sediment particle sizes } \\ A D V & \text { Acoustic Doppler Velocimeter } \\ C F D & \text { Computational Fluid Dynamics } \\ L N E C & \text { National Laboratory of Civil Engineering } \\ L D V & \text { Laser Doppler Velocimetry } \\ P I V & \text { Particle Image Velocimetry } \\ R S S e s & \left.\text { Reynolds Shear Stresses } \overline{\left(u^{\prime} v^{\prime}\right.}, \overline{u^{\prime} w^{\prime}} \text { and } \overline{v^{\prime} w^{\prime}}\right) \\ S N R & \text { Signal-to-Noise Ratio } \\ & \end{array}$

\section{References}

1. Melville, B.W.; Coleman, S.E. Bridge Scour; Water Resources Publications, LLC: Highlands Ranch, CO, USA, 2000.

2. Arneson, L.; Zevenbergen, L.; Lagasse, P.; Clopper, P. Evaluating Scour at Bridges; Technical Report; Federal Highway Administration: Fort Collins, CO, USA, 2012.

3. Deng, L.; Wang, W.; Yu, Y. State-of-the-Art review on the causes and mechanisms of bridge collapse. J. Perform. Constr. Facil. 2016, 30, 04015005. [CrossRef]

4. Flint, M.M.; Fringer, O.; Billington, S.L.; Freyberg, D.; Diffenbaugh, N.S. Historical analysis of hydraulic bridge collapses in the Continental United States. J. Infrastruct. Syst. 2017, 23, 04017005. [CrossRef]

5. Proske, D. Bridge Collapse Frequencies Versus Failure Probabilities; Springer: Berlin, Germany, 2018.

6. Ettema, R.; Constantinescu, G.; Melville, B.W. Flow-field complexity and design estimation of pier-scour depth: Sixty years since Laursen and Toch. J. Hydraul. Eng. 2017, 143, 03117006. [CrossRef]

7. Dargahi, B. The turbulent flow field around a circular cylinder. Exp. Fluids 1989, 8, 1-12. [CrossRef]

8. Dey, S.; Raikar, R.V. Characteristics of horseshoe vortex in developing scour holes at piers. J. Hydraul. Eng. 2007, 133, 399413.:4(399). [CrossRef]

9. Kumar, A.; Kothyari, U.C.; Raju, K.G.R. Flow structure and scour around circular compound bridge piers-A review. J. Hydro-Environ. Res. 2012, 6, 251-265. [CrossRef]

10. Melville, B.W.; Raudkivi, A.J. Flow characteristics in local scour at bridge piers. J. Hydraul. Res. 1977, 15, 373-380. [CrossRef]

11. Dey, S. Three-dimensional vortex flow field around a circular cylinder in a quasi-equilibrium scour hole. Sadhana 1995, 20, 871-885. [CrossRef]

12. Beheshti, A.A.; Ataie-Ashtiani, B. Experimental study of three-dimensional flow field around a complex bridge pier. J. Eng. Mech. 2010, 136, 143-154. [CrossRef]

13. Beheshti, A.A.; Ataie-Ashtiani, B. Scour hole influence on turbulent flow field around complex bridge piers. Flow Turbul. Combust. 2016, 97, 451-474. [CrossRef]

14. Devenport, W.J.; Simpson, R.L. Time-depeiident and time-averaged turbulence structure near the nose of a wing-body junction. J. Fluid Mech. 1990, 210, 23-55. [CrossRef]

15. Said, N.M.; Mhiri, H.; Bournot, H.; Le Palec, G. Experimental and numerical modelling of the three-dimensional incompressible flow behaviour in the near wake of circular cylinders. J. Wind Eng. Ind. Aerodyn. 2008, 96, 471-502. [CrossRef]

16. Apsilidis, N.; Diplas, P.; Dancey, C.L.; Bouratsis, P. Time-resolved flow dynamics and Reynolds number effects at a wall-cylinder junction. J. Fluid Mech. 2015, 776, 475-511. [CrossRef]

17. Jenssen, U.; Manhart, M. Flow around a scoured bridge pier: A stereoscopic PIV analysis. Exp. Fluids 2020, 61, 1-18. [CrossRef]

18. Ataie-Ashtiani, B.; Aslani-Kordkandi, A. Flow field around single and tandem piers. Flow Turbul. Combust. 2013, 90, 471-490. [CrossRef] 
19. Link, O.; González, C.; Maldonado, M.; Escauriaza, C. Coherent structure dynamics and sediment particle motion around a cylindrical pier in developing scour holes. Acta Geophys. 2012, 60, 1689-1719. [CrossRef]

20. Kirkil, G.; Constantinescu, G. Effects of cylinder Reynolds number on the turbulent horseshoe vortex system and near wake of a surface-mounted circular cylinder. Phys. Fluids 2015, 27, 075102. [CrossRef]

21. Li, J.; Yang, Y.; Yang, Z. Influence of scour development on turbulent flow field in front of a bridge pier. Water 2020, 12, 2370. [CrossRef]

22. Graf, W.; Yulistiyanto, B. Experiments on flow around a cylinder; the velocity and vorticity fields. J. Hydraul. Res. 1998, 36, 637-654. [CrossRef]

23. Roulund, A.; Sumer, B.M.; Fredsøe, J.; Michelsen, J. Numerical and experimental investigation of flow and scour around a circular pile. J. Fluid Mech. 2005, 534, 351-401. [CrossRef]

24. Vijayasree, B.; Eldho, T.; Mazumder, B. Turbulence statistics of flow causing scour around circular and oblong piers. J. Hydraul. Res. 2020, 58, 673-686. [CrossRef]

25. Pasupuleti, L.N.; Timbadiya, P.V.; Patel, P.L. Flow Field Measurements Around Isolated, Staggered, and Tandem Piers on a Rigid Bed Channel. Int. J. Civ. Eng. 2021, pp. 1-18.

26. Chiew, Y.M.; Melville, B.W. Local scour around bridge piers. J. Hydraul. Res. 1987, 25, 15-26. [CrossRef]

27. Bento, A.M.; Couto, L.; Viseu, T.; Pêgo, J.P. Image-Based Techniques for the Advanced Characterization of Scour around Bridge Piers in Laboratory. Available online: https:/ / www.e3s-conferences.org/articles/e3sconf/abs/2018/15/e3sconf_riverflow2018_ 05066/e3sconf_riverflow2018_05066.html (accessed on 4 September 2021)

28. Bento, A.M. Risk-Based Analysis of Bridge Scour Prediction. Ph.D. Thesis, Faculdade de Engenharia da Universidade do Porto, Porto, Portugal, 2021.

29. Lee, S.O.; Hong, S.H. Turbulence characteristics before and after scour upstream of a scaled-down bridge pier model. Water 2019, 11, 1900. [CrossRef]

30. García, C.M.; Cantero, M.I.; Niño, Y.; García, M.H. Turbulence measurements with Acoustic Doppler Velocimeters. J. Hydraul. Eng. 2005, 131, 1062-1073.:12(1062). [CrossRef]

31. Montero, V.G.G.; Romagnoli, M.; García, C.M.; Cantero, M.I.; Scacchi, G. Optimization of ADV sampling strategies using DNS of turbulent flow. J. Hydraul. Res. 2014, 52, 862-869. [CrossRef]

32. Bento, A.M.; Pêgo, J.P.; Couto, L.; Viseu, T. Assessing the flow field around an oblong bridge pier. Vectrino acquisition time sensitivity analysis. Publ. Inst. Geophys. Pol. Acad. Sci. Geophys. Data Bases Process. Instrum. 2021, 434, 131-132._pas_publs-2021038. [CrossRef]

33. Yang, S.Q.; Tan, S.K.; Lim, S.Y. Velocity distribution and dip-phenomenon in smooth uniform open channel flows. J. Hydraul. Eng. 2004, 130, 1179-1186.:12(1179). [CrossRef]

34. Cardoso, A.H.; Graf, W.H.; Gust, G. Uniform flow in a smooth open channel. J. Hydraul. Res. 1989, 27, 603-616. [CrossRef]

35. Kirkil, G.; Constantinescu, S.G.; Ettema, R. Coherent structures in the flow field around a circular cylinder with scour hole. J. Hydraul. Eng. 2008, 134, 572-587.:5(572). [CrossRef]

36. Chang, W.Y.; Constantinescu, G.; Lien, H.C.; Tsai, W.F.; Lai, J.S.; Loh, C.H. Flow structure around bridge piers of varying geometrical complexity. J. Hydraul. Eng. 2013, 139, 812-826. [CrossRef]

37. Schlichting, H.; Gersten, K. Boundary-Layer Theory; Springer: Berlin/Heidelberg, 2017. [CrossRef]

38. Cardoso, A.H.; Cunha, L.V.d. Hidráulica Fluvial; Fundação Calouste Gulbenkian: Lisbon, Portugal, 1998.

39. Nikora, V.; Nokes, R.; Veale, W.; Davidson, M.; Jirka, G. Large-scale turbulent structure of uniform shallow free-surface flows. Environ. Fluid Mech. 2007, 7, 159-172. [CrossRef]

40. Ouro, P.; Juez, C.; Franca, M. Drivers for mass and momentum exchange between the main channel and river bank lateral cavities. Adv. Water Resour. 2020, 137, 103511. [CrossRef]

41. Pandey, M.; Sharma, P.K.; Ahmad, Z.; Singh, U.K.; Karna, N. Three-dimensional velocity measurements around bridge piers in gravel bed. Mar. Georesources Geotechnol. 2017, 36, 663-676. [CrossRef]

42. Raudkivi, A.J. Functional trends of scour at bridge piers. J. Hydraul. Eng. 1986, 112, 1-13:1(1). [CrossRef]

43. Pizarro, A.; Manfreda, S.; Tubaldi, E. The science behind scour at bridge foundations: A review. Water 2020, 12, 374. [CrossRef]

44. Bernard, P.S.; Handler, R.A. Reynolds stress and the physics of turbulent momentum transport. J. Fluid Mech. 1990, 220, 99-124. [CrossRef]

45. Carnacina, I.; Leonardi, N.; Pagliara, S. Characteristics of flow structure around cylindrical bridge piers in pressure-flow conditions. Water 2019, 11, 2240. [CrossRef]

46. Guan, D.; Chiew, Y.M.; Wei, M.; Hsieh, S.C. Characterization of horseshoe vortex in a developing scour hole at a cylindrical bridge pier. Int. J. Sediment Res. 2019, 34, 118-124. [CrossRef] 